CrossMark \& click for updates

Cite this: Phys. Chem. Chem. Phys., 2015, 17, 19874

Received 6th May 2015

Accepted 26th June 2015

DOI: $10.1039 / c 5 c p 02625 c$

www.rsc.org/pccp

\title{
Configuration coordinate energy level diagrams of intervalence and metal-to-metal charge transfer states of dopant pairs in solids
}

\author{
Zoila Barandiarán, ${ }^{a b}$ Andries Meijerink ${ }^{c}$ and Luis Seijo*ab
}

\begin{abstract}
Configuration coordinate diagrams, which are normally used in a qualitative manner for the energy levels of active centers in phosphors, are quantitatively obtained here for intervalence charge transfer (IVCT) states of mixed valence pairs and metal-to-metal charge transfer (MMCT) states of heteronuclear pairs, in solid hosts. The procedure relies on vibrational frequencies and excitation energies of single-ion active centers, and on differences between ion-ligand distances of the donor and the acceptor, which are attainable empirically or through ab initio calculations. The configuration coordinate diagrams of the $\mathrm{Yb}^{2+} / \mathrm{Yb}^{3+}$ mixed-valence pair in $\mathrm{Yb}$-doped $\mathrm{YAG}$ and the $\mathrm{Ce}^{3+} / \mathrm{Yb}^{3+}$ heteronuclear pair in $\mathrm{Ce}, \mathrm{Yb}$-codoped YAG, are obtained and described. They are drawn from empirical data of the single-ions and their usefulness is discussed. The first diagram suggests that IVCT states of $\mathrm{Yb}^{2+} / \mathrm{Yb}^{3+}$ pairs may play an important role in the quenching of the $\mathrm{Yb}^{3+}$ emission and it provides the details of the quenching mechanism. The second diagram supports the interpretation recently given for the energy transfer from $\mathrm{Ce}^{3+}$ to $\mathrm{Yb}^{3+}$ in $\mathrm{Ce}, \mathrm{Yb}$-codoped YAG via a MMCT Ce $\mathrm{Ce}^{4+}-\mathrm{Yb}^{2+}$ state and it provides the details. The analyses of the two diagrams suggest the formation of $\mathrm{Yb}^{2+} / \mathrm{Yb}^{3+}$ pairs after the $\mathrm{Ce}^{3+}-\mathrm{to}-\mathrm{Yb}^{3+} \mathrm{MMCT}$, which is responsible for the temperature quenching of the $\mathrm{Yb}^{3+}$ emission excited via $\mathrm{Ce}^{3+}(4 \mathrm{f} \rightarrow 5 \mathrm{~d})$ absorption in Ce,Yb-codoped YAG.
\end{abstract}

\section{Introduction}

Electron transfer between two metal ions involved in a redox process is an important phenomenon in biology, chemistry, and materials science. It is often known as metal-to-metal charge transfer (MMCT). When the two metal ions differ only in the oxidation state, the conventional name of this process is intervalence charge transfer (IVCT). ${ }^{1}$ [The term IVCT is used sometimes for MMCT between non-equivalent metal ions and also for electron transfer processes not involving metals; here we will adopt the conventional meaning and we will call IVCT only to the homonuclear, symmetric MMCT.]

MMCT states are considered to have an important role in energy transfer processes between optically active centers of doped solids and in non-radiative decays which can drastically change the optical behavior of materials. ${ }^{2}$ The blue to near-infrared conversion in $\mathrm{Ce}^{3+}, \mathrm{Yb}^{3+}$-codoped YAG (ref. 3) and the ultaviolet

\footnotetext{
${ }^{a}$ Departamento de Química, Universidad Autónoma de Madrid, 28049 Madrid, Spain.E-mail: luis.seijo@uam.es

${ }^{b}$ Instituto Universitario de Ciencia de Materiales Nicolás Cabrera, Universidad Autónoma de Madrid, 28049 Madrid, Spain

${ }^{c}$ Condensed Matter and Interfaces, Debye Institute for Nanomaterials Science, Utrecht University, Princetonplein 5, 3584 CC Utrecht, The Netherlands
}

to greenish-blue or to red conversions in $\mathrm{Pr}^{3+}$-doped $\mathrm{CaTiO}_{3}$ and $\mathrm{CaZrO}_{3}$ (ref. 4) are respective examples.

IVCT absorption, which has been found in a large number of mixed-valence molecular compounds, ${ }^{5,6}$ has also been reported in lanthanide activated phosphors like $\mathrm{Ce}^{3+}$-doped $\mathrm{LaPO}_{4}$ (ref. 7), and lanthanide mixed-valence solids like $\mathrm{Na}_{5} \mathrm{Eu}_{7} \mathrm{Cl}_{22}$ (ref. 8). And IVCT luminescence has recently been reported to exist as well, and to be responsible for the anomalous emission of $\mathrm{Ce}^{3+}$ in elpasolites ${ }^{9}$ and $\mathrm{Yb}^{2+}$ in fluorites. ${ }^{10}$ In fact, the IVCT states of mixed-valence pairs in doped solids have a high potential for changing the absorption, emission, and non-radiative decays of the materials when the pairs are formed, because these states are intercalated between the regular states of single-ion active centers. ${ }^{9,10}$ Hence a detailed knowledge of the IVCT states in materials where such mixed-valence pairs are likely to form is important. Among others, this could be the case of solids activated by $\mathrm{Ce}^{3+}, \mathrm{Pr}^{3+}, \mathrm{Eu}^{2+}$, or $\mathrm{Yb}^{2+}$ lanthanide dopants, in which preventing the coexistence of several valence states is difficult. ${ }^{11,12}$

It is common to address the participation of MMCT and IVCT states in energy transfer, non-radiative decay, and radiative processes with the help of schematic configuration coordinate energy level diagrams ${ }^{2-4,7}$ ( $c f$. Fig. 4 in ref. 7, for instance). Here, we present an alternative to make quantitative IVCT and MMCT configuration coordinate diagrams using structural and energetic 
data of the single-ion active centers, which are attainable empirically or through ab initio calculations. We discuss their meaning and use them as interpretative tools for the issues mentioned above.

As bases for the elaboration of the IVCT and MMCT configuration coordinate diagrams, we take the vibronic model for the IVCT absorption of the two-state problem of a mixed-valence pair of Piepho et $a .^{13}$ and its extension to excited states, which was used to analyze state-of-the-art $a b$ initio calculations of the diabatic potential energy surfaces of $\mathrm{Ce}^{3+} / \mathrm{Ce}^{4+}$ and $\mathrm{Yb}^{2+} / \mathrm{Yb}^{3+}$ pairs of dopant ions in solids. ${ }^{9,10}$ The latter revealed that even though adiabatic potential energy surfaces calculated by a full consideration of electronic couplings between electronic states of donor and acceptor centres are necessary for IVCT absorption and emission intensities and non-radiative decay rates, a great deal of quantitative spectroscopic information on the pairs can be attained at the diabatic level, i.e. without explicit consideration of donor-acceptor electronic couplings. Hence, we focus here on the diabatic approximation to configuration coordinate diagrams.

We discuss the definition of the configuration coordinate of a single-ion active center and its corresponding energy level diagram in Section II. This serves as a basis for the definition of the IVCT configuration coordinate of a mixed-valence pair in Section III, where the corresponding energy level diagram is discussed. The same is done for the MMCT states of a heteronuclear metalic pair in Section IV. Detailed discussions of IVCT and MMCT sample cases are given: the $\mathrm{Yb}^{2+} / \mathrm{Yb}^{3+}$ mixed-valence pair in YAG, Section III.B, and the $\mathrm{Ce}^{3+} / \mathrm{Yb}^{3+}$ heteronuclear pair in YAG, Section IV.B.

\section{Configuration coordinate of a single ion active center}

Let us briefly discuss on the configuration coordinate of a single ion active center and its corresponding configuration coordinate diagram. This diagram is a very useful simplified representation of the variation in energy of the electronic levels of the active center with the nuclear displacements. In this simplified description, only one vibrational coordinate is used, which is called the configuration coordinate, and the diagram is aimed at providing gross details of the crossings and relative positions of the electronic levels. Fine details, such as Jahn-Teller distortions, demand the use of several vibrational coordinates.

Let us consider the energies of the electronic levels of an optically active center with a single ion in the absence of (JahnTeller) vibronic couplings between degenerate states. The potential energy surface of the active center in its ground state can be written as a function of its normal vibrational coordinates as

$$
E_{0}\left(Q_{1}, Q_{2}, \ldots\right)=\frac{1}{2} \sum_{\mu}^{N_{\mathrm{TS}}} k_{\mu 0} Q_{\mu}{ }^{2}+\frac{1}{2} \sum_{\nu}^{N_{\mathrm{NTS}}} k_{\nu 0} Q_{\nu}{ }^{2}+\ldots
$$

In this expression, the ground state electronic energy at equilibrium is taken as a reference for the energy scale, and the equilibrium structure is the reference for the vibrational coordinates. In eqn (1), the leading terms are quadratic and diagonal, and, for convenience, we have divided the normal modes into $N_{\mathrm{TS}}$ totally symmetric, $\left\{Q_{\mu}\right\}$, and $N_{\text {NTS }}$ non-totally symmetric, $\left\{Q_{\nu}\right\}$. Then, the energy of an excited electronic state, $E_{i}$, can be written as

$$
\begin{aligned}
E_{i}\left(Q_{1}, Q_{2}, \ldots\right)= & E_{i, e}+\frac{1}{2} \sum_{\mu}^{N_{\mathrm{TS}}} k_{\mu i}\left(Q_{\mu}-Q_{\mu i}\right)^{2} \\
& +\frac{1}{2} \sum_{\nu}^{N_{\mathrm{NTS}}} k_{\nu i} Q_{\nu}{ }^{2}+\ldots
\end{aligned}
$$

Here, $E_{i, e}$ is the the minimum-to-minimum excitation energy from the ground state (vertical offset), $Q_{\mu i}$ is the vibrational offset of the $Q_{\mu}$ totally symmetric normal mode with the ground state (horizontal offset), and it is clear that non-totally symmetric normal modes have null offsets (because symmetry makes all linear $Q_{\nu}$ terms of the electronic energy vanish). Eqn (2) implies that non-totally symmetric normal modes only contribute to the electronic energy difference if the respective force constants are different, e.g. $k_{\nu 0} \neq k_{\nu i}$. Usually, such contributions are much smaller than those due to vibrational equilibrium offsets. So, the leading term of $E_{i}-E_{0}$ is due to the totally symmetric vibrational modes,

$$
\begin{aligned}
E_{i}\left(Q_{1}, Q_{2}, \ldots\right)-E_{0}\left(Q_{1}, Q_{2}, \ldots\right)= & E_{i, e}+\frac{1}{2} \sum_{\mu}^{N_{\mathrm{TS}}} k_{\mu i}\left(Q_{\mu}-Q_{\mu i}\right)^{2} \\
& -\frac{1}{2} \sum_{\mu}^{N_{\mathrm{TS}}} k_{\mu 0} Q_{\mu}{ }^{2}+\ldots
\end{aligned}
$$

In some highly symmetric active centers, like $\mathrm{O}_{\mathrm{h}}$ octahedral $\mathrm{ML}_{6}$ sites and cubic $\mathrm{ML}_{8}$ sites, only the breathing modes are totally symmetric. In these cases, if the vibration of the first coordination shell is the only relevant vibration, then one single breathing mode contributes in eqn (3),

$$
Q_{\text {breath }}=\frac{1}{\sqrt{n}}\left(\delta_{L_{1}}+\delta_{L_{2}}+\cdots+\delta_{L_{n}}\right)
$$

with $n$ being the number of breathing ligands and $\delta_{L_{i}}$ the increment of the $M-L_{i}$ distance with respect to its value in the reference structure.

In a more general case, it is convenient to define a configuration coordinate. In effect, we can make a rotation (unitary transformation) of the $N_{\text {TS }}$ totally symmetric vibrational coordinates into a new set $\left\{Q_{\mu^{\prime}}\right\}$, such that one of the transformed coordinates connects directly the minima of the ground and excited states. Let us call this coordinate $Q_{\text {eff. }}$ (We represent in Fig. 1 the original and transformed coordinates in the case of two totally symmetric coordinates $Q_{1}$ and $Q_{2}$.) Then, $E_{i}$ and $E_{0}$ will have a horizontal offset in this coordinate $Q_{\text {eff }}$, but their offset in all other vibrational coordinates will be zero. Accordingly, only the $Q_{\text {eff }}$ vibrational mode contributes to the leading term of the $E_{i}-E_{0}$ energy difference,

$$
\begin{aligned}
E_{i}\left(Q_{1}, Q_{2}, \ldots\right)-E_{0}\left(Q_{1}, Q_{2}, \ldots\right)= & E_{i, e}+\frac{1}{2} k_{\mathrm{eff}, i}\left(Q_{\mathrm{eff}}-Q_{\mathrm{eff}, i}\right)^{2} \\
& -\frac{1}{2} k_{\mathrm{eff}, 0} Q_{\mathrm{eff}}{ }^{2}+\ldots
\end{aligned}
$$

$Q_{\text {eff }}$ is, then, the configuration coordinate of the single ion active center, because it is the only one with the horizontal 

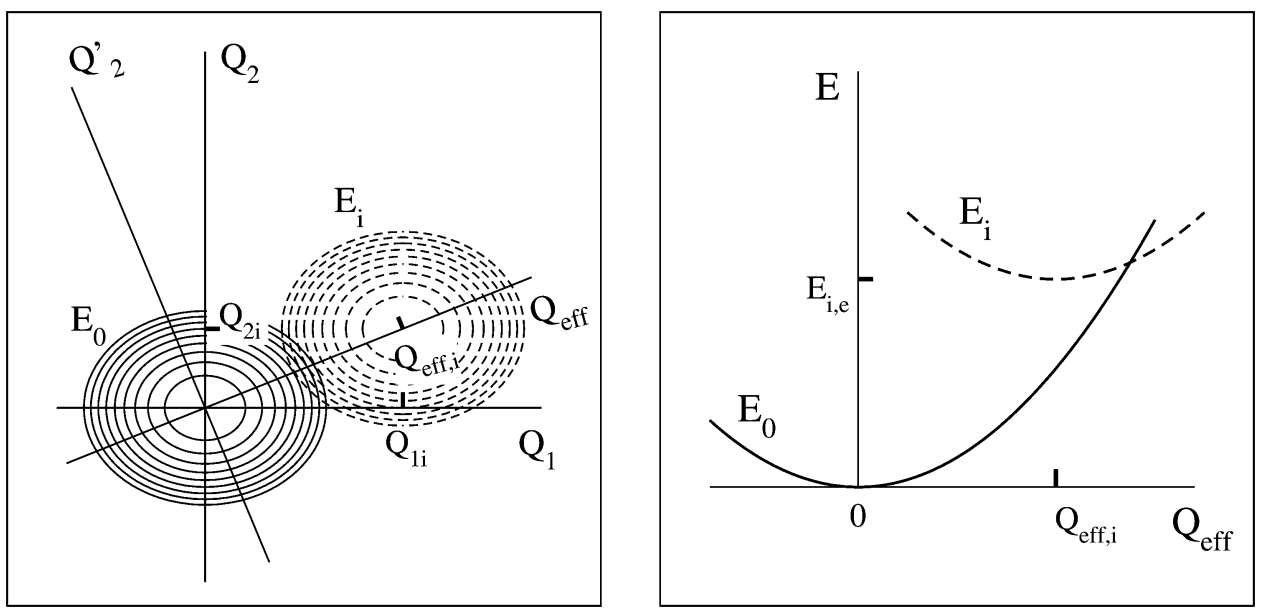

Fig. 1 Left: Definition of the configuration coordinate $Q_{\text {eff }}$ of a single ion active center with two totally symmetric normal vibrational modes $Q_{1}$ and $Q_{2}$. The ground state $E_{0}$ and one excited state $E_{i}$ potential energy surfaces are shown. Right: Corresponding configuration coordinate energy diagram.

offset and the only one that contributes to the leading term of the electronic energy differences.

[We may remark that this configuration coordinate for the potential energy surfaces of two states (ground and excited) is totally equivalent to the reaction coordinate defined between two minima of the potential energy surface of a chemical reaction (reactants and products). Accordingly, for higher-order approximations to the state energies in eqn (3), the configuration coordinate is not exactly the straight line connecting the minima, but the curve that connects the lowest energy crossing point between the two surfaces with the two minima, with the maximum descendent slope. However, we will assume that the quadratic approximation is valid for our purposes.]

We must bear in mind that, in general, the transformed vibrational coordinates are not normal modes, i.e. there are $Q_{\text {eff }} Q_{\mu^{\prime}}$ off-diagonal quadratic terms contributing to the electronic energies. If these terms are negligible, eqn (5) holds and $Q_{\text {eff }}$ is a real vibrational coordinate that connects the minima of $E_{0}$ and $E_{i}$. Also, if all excited states have their minima aligned with $E_{0}$ and $E_{i}$ in the vibrational space, $Q_{\text {eff }}$ is uniquely defined for all states. In contrast, if $Q_{\text {eff }} Q_{\mu^{\prime}}$ off-diagonal terms are important or the electronic energy minima of all states are far from being aligned, then, for eqn (5) to hold for all excited states, $Q_{\text {eff }}$ must be some sort of not well defined, effective vibrational coordinate. For simplicity, $Q_{\text {eff }}$ is often abbreviated as $Q$. The representation of the energies of the electronic states of the single ion active center along $Q$ is called the configuration coordinate diagram.

\section{IVCT configuration coordinate diagram of a mixed valence pair}

In this section we describe the configuration coordinate diagram of the intervalence charge transfer (IVCT) states of donoracceptor dopant pairs in a solid host. We will take an $\mathrm{Yb}^{2+}$ / $\mathrm{Yb}^{3+}$ mixed valence pair in $\mathrm{Yb}$-doped $\mathrm{YAG}\left(\mathrm{Y}_{3} \mathrm{Al}_{5} \mathrm{O}_{12}\right)$ as a working example. We will assume both $\mathrm{Yb}$ ions substitute for $\mathrm{Y}$ at $\mathrm{a} \mathrm{D}_{2}$ symmetry site with 8-fold oxygen coordination (with long-range
Table 1 Level energies relative to their respective ground states $\left(E_{i, e}\right.$, in $\left.\mathrm{cm}^{-1}\right)$ and an increase of the average $\mathrm{Yb}-\mathrm{O}$ and $\mathrm{Ce}-\mathrm{O}$ distances with respect to their values in the ground states of YAG: $\mathrm{Yb}^{3+}$ and $\mathrm{YAG}: \mathrm{Ce}^{3+}$, respectively $(\Delta d$, in $\AA$ )

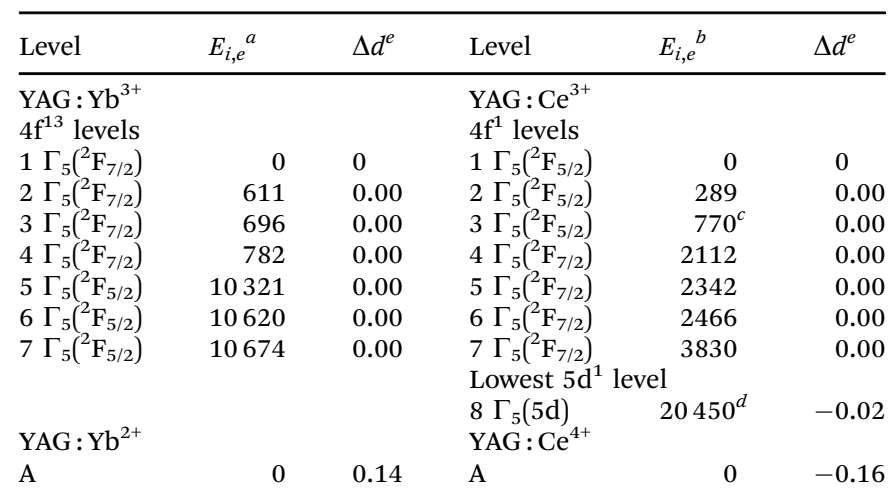

${ }^{a}$ Ref. 14. ${ }^{b}$ Ref. $15 .{ }^{c}$ Ref. $16 .{ }^{d}$ Ref. $17 .{ }^{e}$ See text.

charge compensation in the case of $\mathrm{Yb}^{2+}$ ) and we will focus on the $4 \mathrm{f}^{N}$ manifold. Consequenly, we are interested in the energy levels resulting from the interplay between the $4 \mathrm{f}^{14}$ electronic configuration of $\mathrm{Yb}^{2+}$ and the $4 \mathrm{f}^{13}$ electronic configuration of $\mathrm{Yb}^{3+}$. The $4 \mathrm{f}^{14}$ closed-shell configuration of $\mathrm{Yb}^{2+}$ has a single totally symmetric A state. As is shown in Table 1 , the $4 \mathrm{f}^{13}$ openshell configuration of $\mathrm{Yb}^{3+}$ has seven $\Gamma_{5}$ Kramer's doublets which are grouped into four ${ }^{2} \mathrm{~F}_{7 / 2}$ related levels spanning about $800 \mathrm{~cm}^{-1}$ and three ${ }^{2} \mathrm{~F}_{5 / 2}$ related levels spanning about $500 \mathrm{~cm}^{-1}$ and lying at about $10000 \mathrm{~cm}^{-1}$ above. ${ }^{14}$

Let us label the two distinguishable $\mathrm{Yb}$ dopant atoms of an $\mathrm{Yb}^{2+} / \mathrm{Yb}^{3+}$ mixed valence pair as $\mathrm{Yb}_{\mathrm{L}}$ and $\mathrm{Yb}_{\mathrm{R}}$. Starting with an $\mathrm{Yb}_{\mathrm{L}}{ }^{2+}-\mathrm{Yb}_{\mathrm{R}}{ }^{3+}$ ionic configuration of the pair, we have seven levels with the same relative energies of the $\mathrm{Yb}^{3+}$ levels. Besides these states, we have those that result from electron transfer from $\mathrm{Yb}^{2+}$ to $\mathrm{Yb}^{3+}$. Such electron transfer produces an $\mathrm{Yb}_{\mathrm{L}}{ }^{3+}$ $\mathrm{Yb}_{\mathrm{R}}{ }^{2+}$ ionic configuration of the pair, which also has seven levels with the same relative energies of the $\mathrm{Yb}^{3+}$ levels. These are called the IVCT states (of the original, reference $\mathrm{Yb}_{\mathrm{L}}{ }^{2+}-\mathrm{Yb}_{\mathrm{R}}{ }^{3+}$ pair; obviously, the two sets of seven states are each others' IVCT states.) Altogether, the $4 \mathrm{f}^{N}$ manifold of an $\mathrm{Yb}^{2+} / \mathrm{Yb}^{3+}$ 
mixed valence pair in YAG is made of 14 energy levels. The energies of the seven levels of the $\mathrm{Yb}_{\mathrm{L}}{ }^{2+}-\mathrm{Yb}_{\mathrm{R}}{ }^{3+}$ ionic configuration vary with the displacements of the oxygen atoms around $\mathrm{Yb}_{\mathrm{L}}$ and $\mathrm{Yb}_{\mathrm{R}}$, but their differences are very insensitive to these displacements because of the $5 s^{2} 5 p^{6}$ shielding of the $4 \mathrm{f}$ shells. The same is true for the seven levels of the $\mathrm{Yb}_{\mathrm{L}}{ }^{3+}-\mathrm{Yb}_{\mathrm{R}}{ }^{2+}$ ionic configuration. In contrast, the energy differences between the two sets of levels are very much dependent on the positions of the oxygen atoms because they involve ionization at one site and electron attachement at the complementary site. Here we describe this dependence.

\section{A. IVCT model}

In order to facilitate the extension to other mixed valence pairs and to simplify the notation, we well call $\mathrm{Yb}^{2+}$ the donor $\mathrm{D}$ and $\mathrm{Yb}^{3+}$ the acceptor A. More precisely, D and A will not refer to the single $\mathrm{Yb}$ ions, but to the defect centers they create in the solid; usually these are atomic moieties containing the $\mathrm{Yb}$ ions and their first coordination shells at least. Then the $\mathrm{Yb}_{\mathrm{L}}{ }^{2+}-\mathrm{Yb}_{\mathrm{R}}{ }^{3+}$ ionic configuration of the $\mathrm{Yb}^{2+} / \mathrm{Yb}^{3+}$ mixed valence pair can be called $\mathrm{D}_{\mathrm{L}} \mathrm{A}_{\mathrm{R}}$, or simply $\mathrm{DA}$, and the $\mathrm{Yb}_{\mathrm{L}}{ }^{3+}-\mathrm{Yb}_{\mathrm{R}}{ }^{2+}$ ionic configuration $\mathrm{A}_{\mathrm{L}} \mathrm{D}_{\mathrm{R}}$, or simply $\mathrm{AD}$.

Let us describe first the energy of the electronic ground state of the $\mathrm{Yb}^{2+} / \mathrm{Yb}^{3+}$ mixed valence pair as a function of two normal modes $Q_{\mathrm{L}}$ and $Q_{\mathrm{R}}$, which describe vibrations around $\mathrm{Yb}_{\mathrm{L}}$ and $\mathrm{Yb}_{\mathrm{R}}$ respectively. We will comment later on the excited states. We may think of $Q_{\mathrm{L}}$ and $Q_{\mathrm{R}}$ as the configuration coordinates (Section II) of the $\mathrm{Yb}_{\mathrm{L}}$ and $\mathrm{Yb}_{\mathrm{R}}$ active centers. In general, they can be any totally symmetric normal vibrational coordinate of the centers.

The adiabatic ground state energy of the $\mathrm{Yb}^{2+} / \mathrm{Yb}^{3+}$ pair at any value of $Q_{\mathrm{L}}$ and $Q_{\mathrm{R}}$ can be seen as a result of the diagonalization of a $2 \times 2$ Hermitean matrix whose diagonal elements are the energies of the $\mathrm{Yb}_{\mathrm{L}}{ }^{2+}-\mathrm{Yb}_{\mathrm{R}}{ }^{3+}$ and $\mathrm{Yb}_{\mathrm{L}}{ }^{3+}-\mathrm{Yb}_{\mathrm{R}}{ }^{2+}$ ionic configurations of the pair (diabatic energies $H_{11}=E_{\mathrm{D}_{0} \mathrm{~A}_{0}}$ and $H_{22}=E_{\mathrm{A}_{0} \mathrm{D}_{0}}$ ), and with the electronic coupling between the two ionic configurations as the off-diagonal element $H_{12}$. This diagonalization also gives the adiabatic energy of a second, excited state at each $Q_{\mathrm{L}}$ and $Q_{\mathrm{R}}$. The consideration of the $H_{12}$ electronic coupling is central to the energy barrier of the thermal electron transfer reaction $\mathrm{Yb}_{\mathrm{L}}{ }^{2+}-\mathrm{Yb}_{\mathrm{R}}{ }^{3+} \rightarrow \mathrm{Yb}_{\mathrm{L}}{ }^{3+}-\mathrm{Yb}_{\mathrm{R}}{ }^{2+}$ and to the radiative and non-radiative transition probabilities. However, it is of minor importance for the energy of the corresponding optical electron transfer, which takes place at a fixed equilibrium structure of $\mathrm{Yb}_{\mathrm{L}}{ }^{2+}-\mathrm{Yb}_{\mathrm{R}}{ }^{3+}$ with a relatively long $\mathrm{Yb}-\mathrm{Yb}$ distance, and for the values of the vibrational coordinates at which crossings between potential energy surfaces occur. ${ }^{9,10}$ In consequence, we will discuss the diabatic energies of $\mathrm{Yb}_{\mathrm{L}}{ }^{2+}-\mathrm{Yb}_{\mathrm{R}}{ }^{3+}$ and $\mathrm{Yb}_{\mathrm{L}}{ }^{3+}-\mathrm{Yb}_{\mathrm{R}}{ }^{2+}$, which correspond to null electronic coupling between the oxidized and reduced members of the pair.

The diabatic energy of the ground state of the DA ionic configuration, as a function of the positions of the ligands that can be described using the coordinates $Q_{\mathrm{L}}$ and $Q_{\mathrm{R}}$, can be written as

$$
E_{\mathrm{D}_{0} \mathrm{~A}_{0}}\left(Q_{\mathrm{L}}, Q_{\mathrm{R}}\right)=\frac{1}{2} k\left(Q_{\mathrm{L}}-Q_{\mathrm{D}_{0}}\right)^{2}+\frac{1}{2} k\left(Q_{\mathrm{R}}-Q_{\mathrm{A}_{0}}\right)^{2},
$$

in a quadratic approximation with a common force constant for $\mathrm{D}$ and $\mathrm{A}, k=\mu \omega^{2}, \mu$ being the reduced mass of the vibration and $\omega$ the vibrational frequency common to both vibrational coordinates. This equation establishes the minimum of $E_{\mathrm{D}_{0} \mathrm{~A}_{0}}$ as the reference energy. $Q_{\mathrm{D}_{0}}$ and $Q_{\mathrm{A}_{0}}$ are the values of the vibrational coordinates at the equilibrium structures of $\mathrm{D}$ and $\mathrm{A}$ respectively. Equivalently, if the donor and acceptor sites are identical, the diabatic energy of the ground state of the $\mathrm{AD}$ ionic configuration is

$$
E_{\mathrm{A}_{0} \mathrm{D}_{0}}\left(Q_{\mathrm{L}}, Q_{\mathrm{R}}\right)=\frac{1}{2} k\left(Q_{\mathrm{L}}-Q_{\mathrm{A}_{0}}\right)^{2}+\frac{1}{2} k\left(Q_{\mathrm{R}}-Q_{\mathrm{D}_{0}}\right)^{2} .
$$

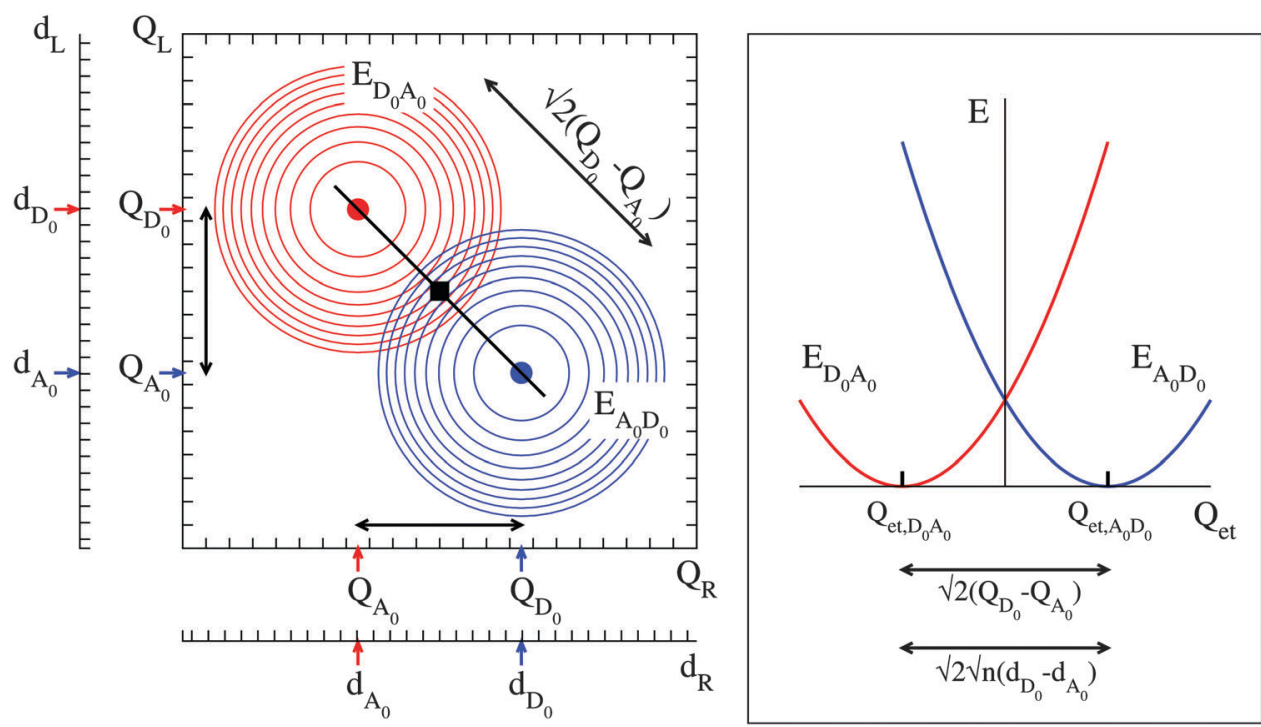

Fig. 2 Left: Ground state diabatic energy surfaces of the DA (red) and AD (blue) ionic configurations of the mixed valence pair. The black line that connects the DA minimum (red dot) with the AD minimum (blue dot) and passes through the activated complex (black square) is the electron transfer reaction coordinate, which is also the IVCT configuration coordinate. Right: IVCT configuration coordinate diagram with the ground state energies of DA (red) and $A D$ (blue). 
The diabatic potential energy surface $E_{\mathrm{A}_{0} \mathrm{D}_{0}}\left(Q_{\mathrm{L}}, Q_{\mathrm{R}}\right)$ is identical to $E_{\mathrm{D}_{0} \mathrm{~A}_{0}}\left(Q_{\mathrm{L}}, Q_{\mathrm{R}}\right)$ but shifted $-\left(Q_{\mathrm{D}_{0}}-Q_{\mathrm{A}_{0}}\right)$ in the $Q_{\mathrm{L}}$ axis and $+\left(Q_{\mathrm{D}_{0}}-Q_{\mathrm{A}_{0}}\right)$ in the $Q_{\mathrm{R}}$ axis. They are represented in Fig. 2.

The crossing point between $E_{\mathrm{D}_{0} \mathrm{~A}_{0}}$ and $E_{\mathrm{A}_{0} \mathrm{D}_{0}}$ with lowest energy is the activated complex (ac) of the thermal DA $\rightarrow \mathrm{AD}$ electron transfer reaction at the diabatic level. Within the adopted approximations of identical D and A sites and a common force constant for both, this activated complex is at the midpoint between their respective minima: $Q_{\mathrm{L}, \mathrm{ac}}=Q_{\mathrm{R}, \mathrm{ac}}=$ $Q_{\mathrm{ac}} \equiv\left(Q_{\mathrm{D}_{0}}+Q_{\mathrm{A}_{0}}\right) / 2$. The electron transfer reaction coordinate is the straight line in the $\left(Q_{\mathrm{L}}, Q_{\mathrm{R}}\right)$ plane that connects the $E_{\mathrm{D}_{0} \mathrm{~A}_{0}}$ and $E_{\mathrm{A}_{0} \mathrm{D}_{0}}$ minima and passes through the activated complex,

$$
\frac{Q_{\mathrm{L}}-Q_{\mathrm{D}_{0}}}{Q_{\mathrm{R}}-Q_{\mathrm{A}_{0}}}=-1 \text {. }
$$

Then, a normal electron transfer reaction coordinate $Q_{\text {et }}$ can be defined as

$$
Q_{\mathrm{et}}=\frac{1}{\sqrt{2}}\left(Q_{\mathrm{R}}-Q_{\mathrm{L}}\right)
$$

which is null for the activated complex, $Q_{\text {et,ac }}=0$, and takes opposite values for the $\mathrm{DA}$ and $\mathrm{AD}$ ionic configurations at the equilibrium,

$$
-Q_{\mathrm{et}, \mathrm{D}_{0} \mathrm{~A}_{0}}=Q_{\mathrm{et}, \mathrm{A}_{0} \mathrm{D}_{0}}=\frac{1}{\sqrt{2}}\left(Q_{\mathrm{D}_{0}}-Q_{\mathrm{A}_{0}}\right),
$$

which gives

$$
Q_{\mathrm{et}, \mathrm{A}_{0} \mathrm{D}_{0}}-Q_{\mathrm{et}, \mathrm{D}_{0} \mathrm{~A}_{0}}=\sqrt{2}\left(Q_{\mathrm{D}_{0}}-Q_{\mathrm{A}_{0}}\right) .
$$

Using the $Q_{\text {et }}$ defined in eqn (9), the parametric form of the reaction coordinate is

$$
\left\{\begin{array}{l}
Q_{\mathrm{L}}-Q_{\mathrm{ac}}=-\frac{1}{\sqrt{2}} Q_{\mathrm{et}}, \\
Q_{\mathrm{R}}-Q_{\mathrm{ac}}=+\frac{1}{\sqrt{2}} Q_{\mathrm{et}},
\end{array}\right.
$$

which makes it clear that an increase of $Q_{\text {et }}$ means a simultaneous decrease of $Q_{\mathrm{L}}$ and an increase of $Q_{\mathrm{R}}$. This reflects the fact that a thermal electron transfer from $D_{L}$ to $A_{R}$, which converts $D_{L} A_{R}$ into $A_{L} D_{R}$, is accompanied by a contraction of the coordination shells around the donor $\mathrm{D}_{\mathrm{L}}$ and a simultaneous expansion around the acceptor $A_{R}$.

Accordingly, the energies of the two ionic configurations of the $\mathrm{Yb}^{2+} / \mathrm{Yb}^{3+}$ mixed valence pair along the reaction coordinate are:

$$
\begin{gathered}
E_{\mathrm{D}_{0} \mathrm{~A}_{0}}\left(Q_{\mathrm{et}}\right)=\frac{1}{2} k\left(Q_{\mathrm{et}}-Q_{\mathrm{et}, \mathrm{D}_{0} \mathrm{~A}_{0}}\right)^{2}, \\
E_{\mathrm{A}_{0} \mathrm{D}_{0}}\left(Q_{\mathrm{et}}\right)=\frac{1}{2} k\left(Q_{\mathrm{et}}-Q_{\mathrm{et}, \mathrm{A}_{0} \mathrm{D}_{0}}\right)^{2},
\end{gathered}
$$

which are two identical parabolae with a horizontal offset $\sqrt{2}\left(Q_{\mathrm{D}_{0}}-Q_{\mathrm{A}_{0}}\right)$,

$$
E_{\mathrm{D}_{0} \mathrm{~A}_{0}}\left(Q_{\mathrm{et}}-\sqrt{2}\left(Q_{\mathrm{D}_{0}}-Q_{\mathrm{A}_{0}}\right)\right)=E_{\mathrm{A}_{0} \mathrm{D}_{0}}\left(Q_{\mathrm{et}}\right) .
$$

Since the coordinate orthogonal to $Q_{\text {et }}$ does not have a horizontal offset (Fig. 2), the reaction coordinate $Q_{\text {et }}$ is the IVCT configuration coordinate. The horizontal offset and the force constant $k$ are the only two degrees of freedom of this model.

If $Q_{\mathrm{L}}$ and $Q_{\mathrm{R}}$ are the respective breathing modes of the $\mathrm{Yb}_{\mathrm{L}}$ and $\mathrm{Yb}_{\mathrm{R}}$ substitutional defects in $\mathrm{YAG}$, which normally produce the maximum energy changes, they can be written as

$$
\begin{aligned}
Q_{\mathrm{L}} & =\frac{1}{\sqrt{8}}\left(\delta_{\mathrm{O}_{\mathrm{L}_{1}}}+\delta_{\mathrm{O}_{\mathrm{L}_{2}}}+\cdots+\delta_{\mathrm{O}_{\mathrm{L}_{8}}}\right), \\
Q_{\mathrm{R}} & =\frac{1}{\sqrt{8}}\left(\delta_{\mathrm{O}_{\mathrm{R}_{1}}}+\delta_{\mathrm{O}_{\mathrm{R}_{2}}}+\cdots+\delta_{\mathrm{O}_{\mathrm{R}_{8}}}\right),
\end{aligned}
$$

with $\delta_{\mathrm{O}_{L_{1}}}$ being the increase of the $\mathrm{Yb}_{\mathrm{L}}-\mathrm{O}_{\mathrm{L}_{1}}$ distance with respect to its value in a given reference structure, and equivalently for the displacements of the other oxygen atoms. The electron transfer reaction coordinate $Q_{\text {et }}$ defined in eqn (9) that corresponds to these definitions of $Q_{\mathrm{L}}$ and $Q_{\mathrm{R}}$ are shown in Fig. 3. Since all the $\mathrm{Yb}-\mathrm{O}$ distances change equally during breathing, we can write

$$
\begin{aligned}
Q_{\mathrm{L}} & =\sqrt{8}\left(d_{\mathrm{L}}-d_{\mathrm{ref}}\right), \\
Q_{\mathrm{R}} & =\sqrt{8}\left(d_{\mathrm{R}}-d_{\mathrm{ref}}\right),
\end{aligned}
$$

where $d_{\text {ref }}, d_{\mathrm{L}}$, and $d_{\mathrm{R}}$ are, respectively, the average $\mathrm{Yb}-\mathrm{O}$ distances in a reference structure, and around $\mathrm{Yb}_{\mathrm{L}}$ and $\mathrm{Yb}_{\mathrm{R}}$ at any moment. Then, for the donor and acceptor equilibrium structures we have

$$
\begin{aligned}
Q_{\mathrm{D}_{0}} & =\sqrt{8}\left(d_{\mathrm{D}_{0}}-d_{\mathrm{ref}}\right), \\
Q_{\mathrm{A}_{0}} & =\sqrt{8}\left(d_{\mathrm{A}_{0}}-d_{\mathrm{ref}}\right),
\end{aligned}
$$

with $d_{\mathrm{D}_{0}}$ and $d_{\mathrm{A}_{0}}$ being the average $\mathrm{Yb}-\mathrm{O}$ distances around the donor $\mathrm{Yb}^{2+}$ and the acceptor $\mathrm{Yb}^{3+}$ at equilibrium. In a more general case with a coordination number $n$ of equal ligands,

$$
\begin{aligned}
Q_{\mathrm{D}_{0}} & =\sqrt{n}\left(d_{\mathrm{D}_{0}}-d_{\mathrm{ref}}\right), \\
Q_{\mathrm{A}_{0}} & =\sqrt{n}\left(d_{\mathrm{A}_{0}}-d_{\mathrm{ref}}\right) .
\end{aligned}
$$

This leads to the centers of the two parabolae in the configuration coordinate diagram (eqn 13),

$$
-Q_{\mathrm{et}, \mathrm{D}_{0} \mathrm{~A}_{0}}=Q_{\mathrm{et}, \mathrm{A}_{0} \mathrm{D}_{0}}=\sqrt{n / 2}\left(d_{\mathrm{D}_{0}}-d_{\mathrm{A}_{0}}\right),
$$

and their offset

$$
\sqrt{2}\left(Q_{\mathrm{D}_{0}}-Q_{\mathrm{A}_{0}}\right)=\sqrt{2 n}\left(d_{\mathrm{D}_{0}}-d_{\mathrm{A}_{0}}\right) .
$$

Then, the horizontal offset (which is key to the model, together with the force constant) can be estimated from the difference
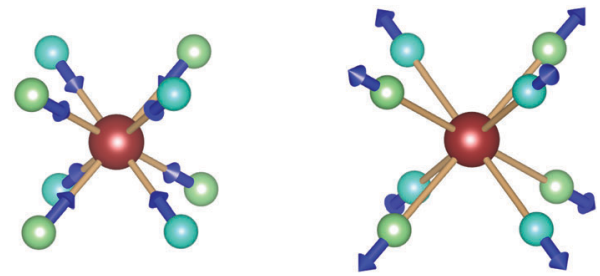

Fig. 3 Electron transfer reaction coordinate $Q_{\mathrm{et}}$ of an $\mathrm{Yb}^{2+} / \mathrm{Yb}^{3+}$ pair in YAG 
between the ionic radii of the donor and acceptor ions, $\mathrm{Yb}^{2+}$ and $\mathrm{Yb}^{3+}$ in our working example.

The diabatic potential energy surfaces of other states of the $4 \mathrm{f}^{N}$ manifold of the $\mathrm{Yb}^{2+} / \mathrm{Yb}^{3+}$ mixed valence pair can be written as

$$
\begin{gathered}
E_{\mathrm{D}_{i} \mathrm{~A}_{j}}\left(Q_{\mathrm{L}}, Q_{\mathrm{R}}\right)=E_{\mathrm{D}_{i} \mathrm{~A}_{j}, e}+\frac{1}{2} k\left(Q_{\mathrm{L}}-Q_{\mathrm{D}_{0}}\right)^{2}+\frac{1}{2} k\left(Q_{\mathrm{R}}-Q_{\mathrm{A}_{0}}\right)^{2} \\
E_{\mathrm{A}_{j} \mathrm{D}_{i}}\left(Q_{\mathrm{L}}, Q_{\mathrm{R}}\right)=E_{\mathrm{D}_{i} \mathrm{~A}_{j}, e}+\frac{1}{2} k\left(Q_{\mathrm{L}}-Q_{\mathrm{A}_{0}}\right)^{2}+\frac{1}{2} k\left(Q_{\mathrm{R}}-Q_{\mathrm{D}_{0}}\right)^{2},
\end{gathered}
$$

assuming that they have the same equilibrium structures and vibrational frequencies as the ground state. The vertical offsets $E_{\mathrm{D}_{t}, j}, e$ are the sum of the minimum-to-minimum excitation energies from the ground state to the $i$ excited state of $\mathrm{D}$ and from the ground state to the $j$ excited state of $\mathrm{A}: E_{\mathrm{D}_{i} \mathrm{~A}_{j}, e}=\left(E_{\mathrm{D}_{i}, e}-E_{\mathrm{D}_{0}, e}\right)+\left(E_{\mathrm{A}_{j} e}-E_{\mathrm{A}_{0}, e}\right)$. Those of the two complementary states $\mathrm{D}_{i} \mathrm{~A}_{j}$ and $\mathrm{A}_{j} \mathrm{D}_{i}$ are identical: then, their energies in the IVCT configuration coordinate diagram are

$$
\begin{gathered}
E_{\mathrm{D}_{i} \mathrm{~A}_{j}}\left(Q_{\mathrm{et}}\right)=E_{\mathrm{D}_{i} \mathrm{~A}_{j}, e}+\frac{1}{2} k\left(Q_{\mathrm{et}}-Q_{\mathrm{et}, \mathrm{D}_{0} \mathrm{~A}_{0}}\right)^{2}, \\
E_{\mathrm{A}_{j} \mathrm{D}_{i}}\left(Q_{\mathrm{et}}\right)=E_{\mathrm{D}_{i} \mathrm{~A}_{j}, e}+\frac{1}{2} k\left(Q_{\mathrm{et}}-Q_{\mathrm{et}, \mathrm{A}_{0} \mathrm{D}_{0}}\right)^{2} .
\end{gathered}
$$

In summary, eqn (22), together with eqn (19), or in a more general case with eqn (10), constitutes an IVCT configuration coordinate (diabatic) diagram of the $\mathrm{D} / \mathrm{A}$ mixed valence pair.

The model of the potential energy surfaces can be improved by extending eqn (21). Using different force constants for D and A leads to a different electron transfer reaction coordinate but a configuration coordinate diagram like eqn (22) can still be used. ${ }^{9}$ In this case, the minima of $\mathrm{DA}$ and $\mathrm{AD}$ are not aligned with the activated complex and the reaction coordinate is made of two straight segments, one between DA and the activated complex and another between the activated complex and AD. Also, using state-specific equilibrium structures, or statespecific force constants, or including anharmonic terms, will prevent from defining a unique reaction coordinate, because there is a different one for each $\mathrm{D}_{i} \mathrm{~A}_{j}-\mathrm{A}_{k} \mathrm{D}_{\ell}$ combination. In the case of excited states of a different configuration, like $4 \mathrm{f}^{N-1} 5 \mathrm{~d}$, using state-specific equilibrium structures, or at least configuration-specific equilibrium structures, might be neccesary. If so, the one-dimension configuration coordinate diagram will break in a strict sense and working with the two-dimension energy surfaces is compulsory. However, the reaction coordinates of several $\mathrm{D}_{i} \mathrm{~A}_{j}-\mathrm{A}_{k} \mathrm{D}_{\ell}$ combinations can be similar enough so as to make the representation of all states of the mixed valence pair along one of these reaction coordinates meaningful. ${ }^{9}$

\section{B. IVCT configuration coordinate diagram of $\mathbf{Y b}^{2+} / \mathbf{Y b}^{3+}$ in YAG}

In Fig. 4 we show the IVCT configuration coordinate diagram of the $4 \mathrm{f}^{N}$ levels of an $\mathrm{Yb}^{2+} / \mathrm{Yb}^{3+}$ mixed valence pair in YAG. It results from using eqn (19) and (22) with $n=8$ and the following data: (1) the $E_{\mathrm{D}_{i} \mathrm{~A}_{j}, e}$ are the experimental $4 \mathrm{f} \rightarrow 4 \mathrm{f}$ excitation energies of $\mathrm{Yb}^{3+}$, which are shown in the second column of Table 1 (note that $\mathrm{Yb}^{2+}$ has only one state of the $4 \mathrm{f}^{14}$ configuration).
(2) For the $d_{\mathrm{D}_{0}}-d_{\mathrm{A}_{0}}$ offset between donor and acceptor equilibrium distances, which is $d_{\mathrm{Yb}^{2+}-\mathrm{O}}-d_{\mathrm{Yb}^{3+}-\mathrm{O}}$, we have taken $90 \%$ of the difference between the ionic radii of $\mathrm{Yb}^{2+}$ and $\mathrm{Yb}^{3+}$ in coordination 8 (1.14 $\AA$ and $0.985 \AA$ respectively, ref. 18), which is $d_{\mathrm{D}_{0}}-d_{\mathrm{A}_{0}}=0.14 \AA$. The reduction factor has been used to take into account the host effect, which has been found to make the equilibrium impurity-ligand distance in a doped host to lie between the cation-ligand distance in the undoped host and the distance that would correspond to the ionic radii mismatch between the host cation and the impurity. ${ }^{19}$ (3) The force constant is $k=\mu \omega^{2}$, with $\mu=m(\mathrm{O})=15.999 \mathrm{amu}$. We are not aware of the direct experimental determinations of the breathing mode vibrational frequency of $\mathrm{Yb}^{3+}$ defects in YAG; we have taken a $\bar{\nu}=\omega /(2 \pi c)=326 \mathrm{~cm}^{-1}$ mode reported by Lupei et $a .^{20}$ after an analysis of resonant vibronic effects in YAG: $\mathrm{Yb}^{3+}$ and have scaled it $0.95 \%$ down to $310 \mathrm{~cm}^{-1}$. This corresponds to a $90 \%$ scaling of the force constant $k$, which is expected to be smaller in $\mathrm{Yb}^{2+}$ than in $\mathrm{Yb}^{3+}$. Since

$$
\frac{k}{\mathrm{~cm}^{-1} \AA^{-2}}=0.029660 \times\left(\frac{\mu}{\mathrm{amu}}\right) \times\left(\frac{\bar{\nu}}{\mathrm{cm}^{-1}}\right)^{2}
$$

we get $k=50434 \mathrm{~cm}^{-1} \AA^{-2}$.

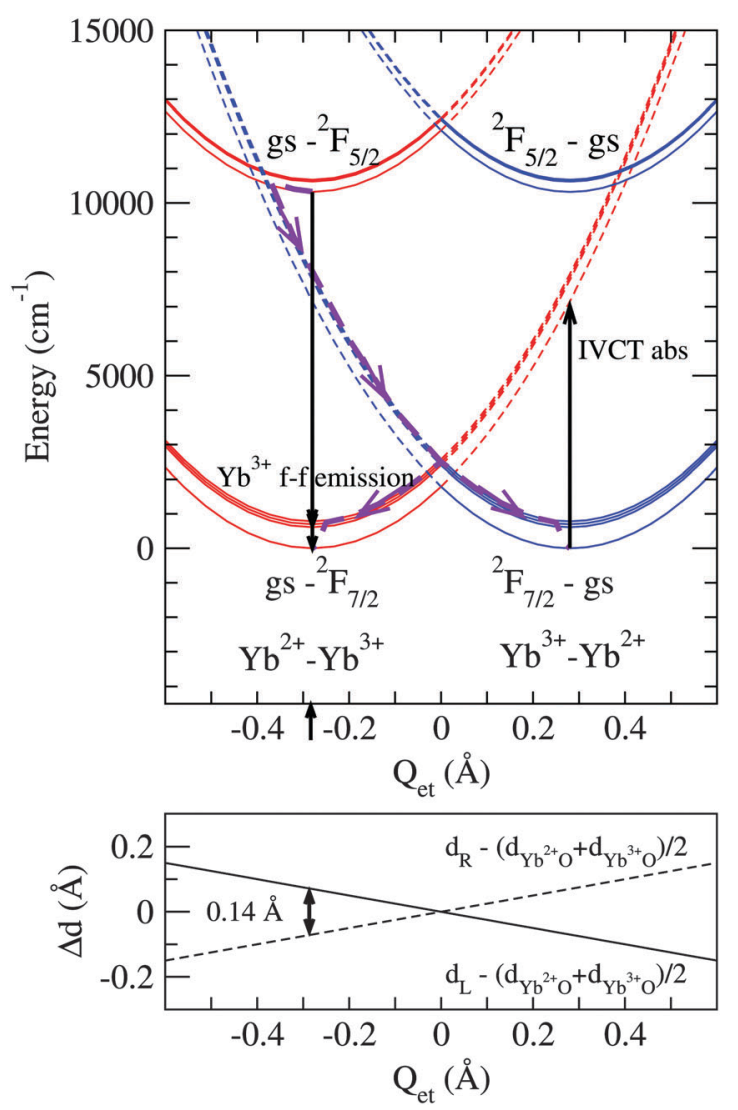

Fig. 4 Top: IVCT configuration coordinate diagram of a $\mathrm{Yb}^{2+} / \mathrm{Yb}^{3+}$ mixed valence pair in YAG. Bottom: Changes of the $\mathrm{Yb}-\mathrm{O}$ distance in the left $\mathrm{Yb}$ $\left(d_{L}\right.$, full line) and right $Y b\left(d_{R}\right.$, dashed line) with respect to their value at the activated complex, $\left(d_{\mathrm{Yb}^{2+-}, \mathrm{O} e}+d_{\mathrm{Yb}^{3+-}, \mathrm{O}, \mathrm{e}}\right) / 2$, along the configuration coordinate (or electron transfer reaction coordinate) $Q_{\mathrm{et}}$. 
In the IVCT configuration coordinate diagram (Fig. 4) we observe the energies of the seven levels of the $\mathrm{Yb}_{\mathrm{L}}{ }^{2+}-\mathrm{Yb}_{\mathrm{R}}{ }^{3+}$ (in red) and the seven levels of the $\mathrm{Yb}_{\mathrm{L}}{ }^{3+}-\mathrm{Yb}_{\mathrm{R}}{ }^{2+}$ (in blue) ionic configurations of the pair. They are grouped in two sets of four levels corresponding to $\mathrm{Yb}_{\mathrm{R}}{ }^{3+}\left({ }^{2} \mathrm{~F}_{7 / 2}\right)$ and $\mathrm{Yb}_{\mathrm{L}}{ }^{3+}\left({ }^{2} \mathrm{~F}_{7 / 2}\right)$, and two sets of three levels about $10000 \mathrm{~cm}^{-1}$ above, corresponding to $\mathrm{Yb}_{\mathrm{R}}{ }^{3+}\left({ }^{2} \mathrm{~F}_{5 / 2}\right)$ and $\mathrm{Yb}_{\mathrm{L}}{ }^{3+}\left({ }^{2} \mathrm{~F}_{5 / 2}\right)$. They have been represented with full lines for configuration coordinate values around their respective minima. We used dashes lines for their energies at configuration coordinate values corresponding to stressed structures. For instance, at $Q_{\mathrm{et}}=-0.28 \AA$ we find $\mathrm{Yb}_{\mathrm{L}}{ }^{2+}-\mathrm{Yb}_{\mathrm{R}}{ }^{3+}$ in equilibrium (full lines), with a long $\mathrm{Yb}_{\mathrm{L}}-\mathrm{O}$ distance and a short $\mathrm{Yb}_{\mathrm{R}}-\mathrm{O}$ distance; in contrast, an $\mathrm{Yb}_{\mathrm{L}}{ }^{3+}-\mathrm{Yb}_{\mathrm{R}}{ }^{2+}$ state is under strong stress in such a structure (dashed lines) and it will relax towards a short $\mathrm{Yb}_{\mathrm{L}}-\mathrm{O}$ distance and a long $\mathrm{Yb}_{\mathrm{R}}-\mathrm{O}$ distance, increasing $Q_{\text {et }}$ and releasing a large reorganization energy (about $7500 \mathrm{~cm}^{-1}$ ). It is clear that structurally stressed IVCT states intercalate between states of the pairs around their equilibrium. Vertical (Frank-Condon) transitions between full lines take place in $\mathrm{Yb}^{3+}$. Vertical transitions between full and dashed lines are IVCT transitions; they end in structurally stressed states and take place between states with large horizontal offsets, which produces very broad bands. IVCT absorptions in mixed valence compounds have long been known; ${ }^{5,6}$ they take place without a corresponding emission. IVCT emissions from higher excited states have been recently reported in mixed valence dopant pairs in solids. They have been found to be responsible for the anomalous emission of $\mathrm{Ce}^{3+}$-doped elpasolites ${ }^{9}$ and for the interplay between anomalous emissions and $5 \mathrm{~d} \rightarrow 4 \mathrm{f}$ emissions in Yb-doped fluorite hosts. ${ }^{10}$ The IVCT emissions have large Stokes shifts associated with large reorganization energies.

It is interesting to observe in the IVCT configuration coordinate diagram that IVCT crossings between the excited $\mathrm{Yb}_{\mathrm{L}}{ }^{2+}$ $\mathrm{Yb}_{\mathrm{R}}{ }^{3+}\left({ }^{2} \mathrm{~F}_{5 / 2}\right)$ and the ground $\mathrm{Yb}_{\mathrm{L}}{ }^{3+}\left({ }^{2} \mathrm{~F}_{7 / 2}\right)-\mathrm{Yb}_{\mathrm{R}}{ }^{2+}$ manifolds can occur with low energy barriers. Obviously, the same is true for their symmetrical counterparts. With the present data we obtain a $200 \mathrm{~cm}^{-1}$ energy barrier from the minimum of the $\mathrm{Yb}_{\mathrm{L}}{ }^{2+}-\mathrm{Yb}_{\mathrm{R}}{ }^{3+}\left({ }^{2} \mathrm{~F}_{5 / 2}\right)$ state (which is the emitting state of the $\mathrm{Yb}^{3+}$ 4f $\rightarrow$ 4f emission) to the crossing between the lowest $\mathrm{Yb}_{\mathrm{L}}{ }^{2+}-$ $\mathrm{Yb}_{\mathrm{R}}{ }^{3+}\left({ }^{2} \mathrm{~F}_{5 / 2}\right)$ level and the highest $\mathrm{Yb}_{\mathrm{L}}{ }^{3+}\left({ }^{2} \mathrm{~F}_{7 / 2}\right)-\mathrm{Yb}_{\mathrm{R}}{ }^{2+}$ level. This result suggests the consideration of the nonradiative $\mathrm{Yb}^{2+}\left(4 \mathrm{f}_{7 / 2}\right) \rightarrow \mathrm{Yb}^{3+}\left(4 \mathrm{f}_{5 / 2}\right)$ electron transfer in $\mathrm{Yb}^{2+} / \mathrm{Yb}^{3+}$ pairs as a possible mechanism responsible for quenching of the $\mathrm{Yb}^{3+}$ emission, which is shown in violet in Fig. 4. This means that $\mathrm{Yb}^{2+} / \mathrm{Yb}^{3+}$ pairs can be the active quenchers in the concentration quenching of the $\mathrm{Yb}^{3+}$ emission. ${ }^{21}$ Also, they can explain the temperature quenching of the $\mathrm{Yb}^{3+}$ emission excited with $\mathrm{Ce}^{3+} 4 \mathrm{f} \rightarrow 5 \mathrm{~d}$ absorption in Ce,Yb-codoped YAG. ${ }^{3}$

The uncertainities of the empirical data used to build the configuration coordinate diagram in Fig. 4 give only a qualitative or semi-quantitative meaning to the energy barrier just discussed. For instance, taking $95 \%$ or $85 \%$ of the ionic radii difference for $d_{\mathrm{Yb}^{2+}-\mathrm{O}}-d_{\mathrm{Yb}^{3+}-\mathrm{O}}$ instead of $90 \%$, leads to $75 \mathrm{~cm}^{-1}$ and $400 \mathrm{~cm}^{-1}$ energy barriers instead of the $200 \mathrm{~cm}^{-1}$ mentioned above. Similarly, using a higher/lower vibrational frequency would decrease/increase the barrier value in this case. Besides, the effective activation energies that are experimentally determined are smaller than the barrier energies calculated from configuration coordinate diagrams because of the effective overlap between vibrational wavefunctions below the crossing points. ${ }^{22}$ Nevertheless, it is clear that a configuration coordinate diagram obtained with reasonable empirical data indicates that a crossing between a potentially emitting level $\mathrm{Yb}_{\mathrm{L}}{ }^{2+}-\mathrm{Yb}_{\mathrm{R}}{ }^{3+}\left({ }^{2} \mathrm{~F}_{5 / 2}\right)$ and $\mathrm{a}$ structurally stressed IVCT ground state level $\mathrm{Yb}_{\mathrm{L}}{ }^{3+}\left({ }^{2} \mathrm{~F}_{7 / 2}\right)-\mathrm{Yb}_{\mathrm{R}}{ }^{2+}$ is likely to occur and it would cause thermal quenching of the $\mathrm{Yb}^{3+}$ 4f $\rightarrow$ 4f emission.

\section{MMCT configuration coordinate diagram of a metal-metal pair}

In this section, we describe the configuration coordinate diagram of the metal-to-metal charge transfer states of a pair of ions of different elements in a solid host. We will take a $\mathrm{Ce}^{3+}-$ $\mathrm{Yb}^{3+}$ pair in Ce,Yb-codoped YAG as a working example. We assume $\mathrm{Ce}^{3+}$ and $\mathrm{Yb}^{3+}$ substitute for $\mathrm{Y}$ at a $\mathrm{D}_{2}$ symmetry site with 8-fold oxygen coordination. Regarding $\mathrm{Ce}^{3+}$, we will focus on its states of the $4 \mathrm{f}^{1}$ configuration and on its lowest $5 \mathrm{~d}^{1}$ state. As is shown in Table 1 , the seven $4 \mathrm{f}^{1}$ states are grouped in three sets: ${ }^{15,16}$ a first set with three levels spanning about $800 \mathrm{~cm}^{-1}$, 1-3 $\Gamma_{5}$; a second set starting at about $2100 \mathrm{~cm}^{-1}$ above the ground sate with three levels spanning at $350 \mathrm{~cm}^{-1}, 4-6 \Gamma_{5}$; and a third set at about $3800 \mathrm{~cm}^{-1}$ above the ground state with one level, $7 \Gamma_{5}$. (This distribution of levels differs from the extended assumption of three ${ }^{2} \mathrm{~F}_{5 / 2}$ related levels and four ${ }^{2} \mathrm{~F}_{7 / 2}$ related levels separated by about $2500 \mathrm{~cm}^{-1}$; a $4 \mathrm{f}$ crystal field splitting of the same size of the $4 \mathrm{f}$ spin-orbit coupling splitting is responsible for the partial break of such assumption. ${ }^{16}$ ) The lowest $5 \mathrm{~d}^{1}$ state is $20450 \mathrm{~cm}^{-1}$ above the ground state. ${ }^{17}$ These levels will combine with the previously described four ${ }^{2} F_{7 / 2}$ related levels and three ${ }^{2} \mathrm{~F}_{5 / 2}$ related levels of $\mathrm{Yb}^{3+}$ (Section III). The result of this combination is four main sets of levels. A first main set of 28 levels of the $\mathrm{Ce}^{3+}\left(4 \mathrm{f}^{1}\right)-\mathrm{Yb}^{3+}\left({ }^{2} \mathrm{~F}_{7 / 2}\right)$ character lies between 0 and $4600 \mathrm{~cm}^{-1}$ and is divided in three subsets: $\left.12 \mathrm{Ce}^{3+}\left(1-3 \Gamma_{5}\right)-\mathrm{Yb}^{3+}\left({ }^{2} \mathrm{~F}_{7 / 2}\right),{ }_{12 \mathrm{Ce}^{3+}(4-6} \Gamma_{5}\right)-\mathrm{Yb}^{3+}\left({ }^{2} \mathrm{~F}_{7 / 2}\right)$, and 4 $\mathrm{Ce}^{3+}\left(7 \Gamma_{5}\right)-\mathrm{Yb}^{3+}\left({ }^{2} \mathrm{~F}_{7 / 2}\right)$. A second main set of 21 levels of the $\mathrm{Ce}^{3+}\left(4 \mathrm{f}^{1}\right)-\mathrm{Yb}^{3+}\left({ }^{2} \mathrm{~F}_{5 / 2}\right)$ character lies between $10300 \mathrm{~cm}^{-1}$ and $14500 \mathrm{~cm}^{-1}$ and is divided in three subsets: $9 \mathrm{Ce}^{3+}\left(1-3 \Gamma_{5}\right)-$ $\mathrm{Yb}^{3+}\left({ }^{2} \mathrm{~F}_{5 / 2}\right), 9 \mathrm{Ce}^{3+}\left(4-6 \quad \Gamma_{5}\right)-\mathrm{Yb}^{3+}\left({ }^{2} \mathrm{~F}_{5 / 2}\right)$, and $3 \mathrm{Ce}^{3+}\left(\begin{array}{ll}7 & \Gamma_{5}\end{array}\right)-$ $\mathrm{Yb}^{3+}\left({ }^{2} \mathrm{~F}_{5 / 2}\right)$. A third main set of 4 levels of $\mathrm{Ce}^{3+}\left(5 \mathrm{~d}_{1}{ }^{1}\right)-$ $\mathrm{Yb}^{3+}\left({ }^{2} \mathrm{~F}_{7 / 2}\right)$ character lies between $20450 \mathrm{~cm}^{-1}$ and $21230 \mathrm{~cm}^{-1}$. Finally a fourth main set of 4 levels of the $\mathrm{Ce}^{3+}\left(5 \mathrm{~d}_{1}{ }^{1}\right)-\mathrm{Yb}^{3+}\left({ }^{2} \mathrm{~F}_{5 / 2}\right)$ character lies between $30770 \mathrm{~cm}^{-1}$ and $31120 \mathrm{~cm}^{-1}$. Between the third and the fourth set, states of $\mathrm{Ce}^{3+}\left(5 \mathrm{~d}_{2}{ }^{1}\right)-\mathrm{Yb}^{3+}\left({ }^{2} \mathrm{~F}_{7 / 2}\right)$ character associated with the second $5 \mathrm{~d}^{1}$ excited state of $\mathrm{Ce}^{3+}$ may appear. Here we will only pay attention to the three first sets.

Electron transfer from $\mathrm{Ce}^{3+}$ to $\mathrm{Yb}^{3+}$ results into a $\mathrm{Ce}^{4+}-\mathrm{Yb}^{2+}$ pair with a closed-shell ground state much more stable than all its excited states. This level may lie between the $\mathrm{Ce}^{3+}-\mathrm{Yb}^{3+}$ states just discussed. Such a consideration has led to propose its involvement in the mechanism of energy transfer from $\mathrm{Ce}^{3+}$ to $\mathrm{Yb}^{3+}$ in $\mathrm{Ce}, \mathrm{Yb}$-codoped $\mathrm{YAG}$, as well as in the quenching of 
the $\mathrm{Ce}^{3+}$-excited $\mathrm{Yb}^{3+}$-emission of this material. ${ }^{3}$ The question we tackle here is how to represent the energies of the levels of the $\mathrm{Ce}^{3+}-\mathrm{Yb}^{3+}$ and $\mathrm{Ce}^{4+}-\mathrm{Yb}^{2+}$ pairs together in a simplified diagram, which is called the MMCT configuration coordinate diagram.

\section{A. MMCT model}

In order to make the notation more general, we will call $\mathrm{Ce}^{3+}$ the donor $\mathrm{D}$ and $\mathrm{Yb}^{3+}$ the acceptor $\mathrm{A}$. After the electron transfer they result into $\mathrm{Ce}^{4+}$ and $\mathrm{Yb}^{2+}$, which will be respectively called $\mathrm{D}^{+}$and $\mathrm{A}^{-}$. As in the IVCT case, $\mathrm{D}, \mathrm{A}, \mathrm{D}^{+}$, and $\mathrm{A}^{-}$refer to the defect centers the respective ions create in the solid, which will be atomic moieties containing at least their first coordination shells, rather than to the single ions. Then, the pair $\mathrm{Ce}^{3+}-\mathrm{Yb}^{3+}$ is $\mathrm{DA}$ and the pair $\mathrm{Ce}^{4+}-\mathrm{Yb}^{2+}$ is $\mathrm{D}^{+} \mathrm{A}^{-}$.

We aim at describing the energies of the states of the $\mathrm{Ce}^{3+}$ $\mathrm{Yb}^{3+}$ and $\mathrm{Ce}^{4+}-\mathrm{Yb}^{2+}$ pairs (DA and $\mathrm{D}^{+} \mathrm{A}^{-}$) as functions of two vibrational coordinates $Q_{\mathrm{D}}$ and $Q_{\mathrm{A}}$, which describe vibrations of the moieties containing $\mathrm{Ce}\left(\mathrm{D}\right.$ and $\left.\mathrm{D}^{+}\right)$and $\mathrm{Yb}\left(\mathrm{A}\right.$ and $\left.\mathrm{A}^{-}\right)$ respectively. Note that in MMCT, contrary to IVCT, D and $\mathrm{D}^{+}$ refer to a different element than $\mathrm{A}_{\text {and }} \mathrm{A}^{-}$, so that there is no need to use the left and right atoms to differentiate them; in other words, Ce is always the left atom and $\mathrm{Yb}$ the right atom. This is why we use $Q_{\mathrm{D}}$ and $Q_{\mathrm{A}}$ here instead of $Q_{\mathrm{L}}$ and $Q_{\mathrm{R}}$. As in IVCT, $Q_{\mathrm{D}}$ and $Q_{\mathrm{A}}$ can be the configuration coordinate described in Section II of the Ce and $\mathrm{Yb}$ active centers, but they can also be other totally symmetric vibrational coordinates of these centers.

The diabatic energy of the ground state of the DA pair, as a function of the positions of the ligands that can be described using the coordinates $Q_{\mathrm{D}}$ and $Q_{\mathrm{A}}$, can be written as

$$
E_{\mathrm{D}_{0} \mathrm{~A}_{0}}\left(Q_{\mathrm{D}}, Q_{\mathrm{A}}\right)=\frac{1}{2} k_{\mathrm{D}}\left(Q_{\mathrm{D}}-Q_{\mathrm{D}_{0}}\right)^{2}+\frac{1}{2} k_{\mathrm{A}}\left(Q_{\mathrm{A}}-Q_{\mathrm{A}_{0}}\right)^{2},
$$

in a quadratic approximation. $Q_{\mathrm{D}_{0}}$ and $Q_{\mathrm{A}_{0}}$ are the values of the vibrational coordinates of the donor and acceptor moieties at the respective equilibrium structures of D and A. $k_{\mathrm{D}}=\mu_{\mathrm{D}} \omega_{\mathrm{D}}{ }^{2}$ and $k_{\mathrm{A}}=\mu_{\mathrm{A}} \omega_{\mathrm{A}}^{2}$ are, respectively, the donor and acceptor force constants, $\mu_{\mathrm{D}}$ and $\mu_{\mathrm{A}}$ their vibrational masses, and $\omega_{\mathrm{D}}$ and $\omega_{\mathrm{A}}$ their vibrational frequencies. As in IVCT, using this equation we are establishing the ground state energy of the DA pair at its minimum as the reference energy.

The diabatic energy of the ground state of the $\mathrm{D}^{+} \mathrm{A}^{-}$pair that results after MMCT from DA can be written as

$$
\begin{aligned}
E_{\mathrm{D}_{0}+\mathrm{A}_{0}-}\left(Q_{\mathrm{D}}, Q_{\mathrm{A}}\right)= & E_{\mathrm{D}_{0}+\mathrm{A}_{0}{ }^{-}, e}+\frac{1}{2} k_{\mathrm{D}}\left(Q_{\mathrm{D}}-Q_{\mathrm{D}_{0}+}\right)^{2} \\
& +\frac{1}{2} k_{\mathrm{A}}\left(Q_{\mathrm{A}}-Q_{\mathrm{A}_{0}-}\right)^{2} .
\end{aligned}
$$

Here, as in the IVCT model of Section III, we assume a common force constant $k_{\mathrm{D}}$ for $\mathrm{D}$ and $\mathrm{D}^{+}$on one side, and $k_{\mathrm{A}}$ for $\mathrm{A}$ and $\mathrm{A}^{-}$ on the other; $Q_{\mathrm{D}_{0}{ }^{+}}$and $Q_{\mathrm{A}_{0}-}$ are the values of the vibrational coordinates of the donor and acceptor moieties at the respective equilibrium structures of $\mathrm{D}^{+}$and $\mathrm{A}^{-} \cdot E_{\mathrm{D}_{0}{ }^{+} \mathrm{A}_{0}{ }^{-}, e}$ is the vertical offset between the minima of the $\mathrm{D}^{+} \mathrm{A}^{-}$and $\mathrm{DA}$ ground state potential energy surfaces. In an empirical approach to the problem, it can be considered an empirical parameter. Also, it might eventually be convenient to regard it as the sum of: (1) the adiabatic ionization potential of $\mathrm{D}$ in the host, $\mathrm{IP}_{\mathrm{D}}$ (energy difference between the ground states of $\mathrm{D}^{+}$and $\mathrm{D}$ at their relaxed structures), (2) the negative adiabatic electron affinity of A in the host, $-\mathrm{EA}_{\mathrm{A}}$ (energy difference between the ground states of $\mathrm{A}^{-}$and $\mathrm{A}$ at their relaxed structures), and (3) the interaction energy change due to the creation of a hole in $\mathrm{D}$ and an electron in $\mathrm{A}$; for long D-A separations, this can be approximated by $\left(q_{\mathrm{A}}-q_{\mathrm{D}}-1\right) / d_{\mathrm{DA}}$, with $d_{\mathrm{DA}}$ being the distance between the donor and the acceptor, and $q_{\mathrm{D}}$ and $q_{\mathrm{A}}$ their respective defect charges:

$$
E_{\mathrm{D}_{0}{ }^{+} \mathrm{A}_{0}{ }^{-}, e}=\mathrm{IP}_{\mathrm{D}}-\mathrm{EA}_{\mathrm{A}}+\left(q_{\mathrm{A}}-q_{\mathrm{D}}-1\right) / d_{\mathrm{DA}} .
$$

The $E_{\mathrm{D}_{0} \mathrm{~A}_{0}}\left(Q_{\mathrm{D}}, Q_{\mathrm{A}}\right)$ and $E_{\mathrm{D}_{0}{ }^{+} \mathrm{A}_{0}-}\left(Q_{\mathrm{D}}, Q_{\mathrm{A}}\right)$ potential energy surfaces are represented on the left hand side of Fig. 5 .

Within these approximations, the activated complex of the thermal $\mathrm{DA} \rightarrow \mathrm{D}^{+} \mathrm{A}^{-}$reaction is in the straight line that connects their minima. Its exact position depends on the value of the energy offset $E_{\mathrm{D}_{0}{ }^{+} \mathrm{A}_{0}{ }^{-}, e}$. In any case, as in the IVCT case, the electron transfer reaction coordinate is the straight line in the $\left(Q_{\mathrm{D}}, Q_{\mathrm{A}}\right)$ plane that passes through the $E_{\mathrm{D}_{0} \mathrm{~A}_{0}}$ and $E_{\mathrm{D}_{0}{ }^{+} \mathrm{A}_{0}-}$ minima,

$$
\frac{Q_{\mathrm{D}}-Q_{\mathrm{D}_{0}}}{Q_{\mathrm{A}}-Q_{\mathrm{A}_{0}}}=m \equiv \frac{Q_{\mathrm{D}_{0}+}-Q_{\mathrm{D}_{0}}}{Q_{\mathrm{A}_{0^{-}}}-Q_{\mathrm{A}_{0}}} .
$$

with a negative slope $m$. Then, a normal reaction coordinate could be defined like in eqn (9), which would be null in the activated complex. However, since the position of the activated complex can be very different for different pairs of $\mathrm{DA}$ and $\mathrm{D}^{+} \mathrm{A}^{-}$states, it can be more convenient to define here the normal reaction coordinate so that it is null for the DA ground state at equlilbrium:

$$
Q_{\mathrm{et}}=\frac{1}{\sqrt{1+m^{2}}}\left[\left(Q_{\mathrm{A}}-Q_{\mathrm{A}_{0}}\right)+m\left(Q_{\mathrm{D}}-Q_{\mathrm{D}_{0}}\right)\right] \text {. }
$$

Then, the parametric form of the reaction coordinate is

$$
\left\{\begin{array}{l}
Q_{\mathrm{D}}-Q_{\mathrm{D}_{0}}=\frac{m}{\sqrt{1+m^{2}}} Q_{\mathrm{et}}, \\
Q_{\mathrm{A}}-Q_{\mathrm{A}_{0}}=\frac{1}{\sqrt{1+m^{2}}} Q_{\mathrm{et}} .
\end{array}\right.
$$

which, with a negative $m$, indicates that an increase of $Q_{\text {et }}$ means a simultaneous decrease of $Q_{\mathrm{D}}$ and an increase of $Q_{\mathrm{A}}$.

Being the only coordinate with a horizontal offset, $Q_{\text {et }}$ is the MMCT configuration coordinate and the energies of the ground states of the $\mathrm{Ce}^{3+}-\mathrm{Yb}^{3+}$ and $\mathrm{Ce}^{4+}-\mathrm{Yb}^{2+}$ pairs as functions of it constitute the configuration coordinate diagram for these states. Using eqn (23), (24) and (28), they are:

$$
\begin{aligned}
E_{\mathrm{D}_{0} \mathrm{~A}_{0}}\left(Q_{\mathrm{et}}\right) & =\frac{1}{2} k_{\mathrm{et}}\left(Q_{\mathrm{et}}-Q_{\mathrm{et}, \mathrm{D}_{0} \mathrm{~A}_{0}}\right)^{2} \\
E_{\mathrm{D}_{0}+\mathrm{A}_{0}-}\left(Q_{\mathrm{et}}\right) & =E_{\mathrm{D}_{0}+\mathrm{A}_{0}-, e}+\frac{1}{2} k_{\mathrm{et}}\left(Q_{\mathrm{et}}-Q_{\mathrm{et}, \mathrm{D}_{0}+} \mathrm{A}_{0}-\right)^{2},
\end{aligned}
$$

with

$$
\begin{aligned}
Q_{\mathrm{et}, \mathrm{D}_{0} \mathrm{~A}_{0}} & =0 \\
Q_{\mathrm{et}, \mathrm{D}_{0}+\mathrm{A}_{0}{ }^{-}} & =\sqrt{\left(Q_{\mathrm{D}_{0}}-Q_{\mathrm{D}_{0}+}\right)^{2}+\left(Q_{\mathrm{A}_{0^{-}}}-Q_{\mathrm{A}_{0}}\right)^{2}},
\end{aligned}
$$



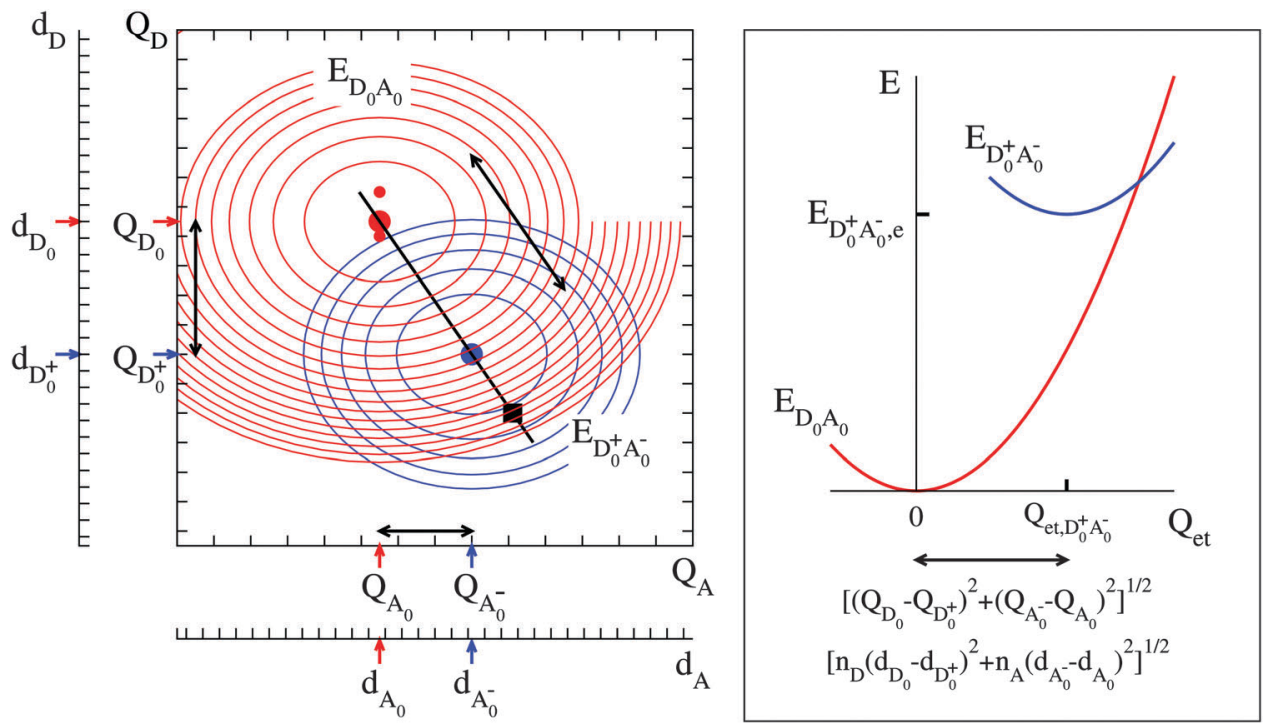

Fig. 5 Left: Ground state diabatic energy surfaces of DA (red) and $D^{+} A^{-}$(blue). The black line that connects the DA minimum (red dot) with the activated complex (black square) and returns to the $\mathrm{D}^{+} \mathrm{A}^{-}$minimum (blue dot) is the electron transfer reaction coordinate, which is also the MMCT configuration coordinate. The minima of other two DA energy surfaces (not represented here) are indicated with red dots. Right: MMCT configuration coordinate diagram with the ground state energies of $\mathrm{DA}\left(\right.$ red) and $\mathrm{D}^{+} \mathrm{A}^{-}$(blue).

and

$$
k_{\mathrm{et}}=\frac{1}{1+m^{2}}\left(m^{2} k_{\mathrm{D}}+k_{\mathrm{A}}\right) .
$$

The MMCT configuration coordinate diagram with $E_{\mathrm{D}_{0} \mathrm{~A}_{0}}\left(Q_{\mathrm{et}}\right)$ and $E_{\mathrm{D}_{0}{ }^{+} \mathrm{A}_{0}}-\left(Q_{\mathrm{et}}\right)$ is represented on the right hand side of Fig. 5. The three degrees of freedom of this MMCT configuration coordinate diagram are the electron transfer reaction coordinate curvature, $k_{\mathrm{et}}$, the MMCT horizontal offset $\sqrt{\left(Q_{\mathrm{D}_{0}}-Q_{\mathrm{D}_{0}+}\right)^{2}+\left(Q_{\mathrm{A}_{0}-}-Q_{\mathrm{A}_{0}}\right)^{2}}$, and the vertical offset $E_{\mathrm{D}_{0}{ }^{+} \mathrm{A}_{0}, e}$.

If $Q_{\mathrm{D}}$ and $Q_{\mathrm{A}}$ are the breathing modes of the donor and the acceptor, with $n_{\mathrm{D}}$ and $n_{\mathrm{A}}$ equal ligands, respectively, we have

$$
\begin{aligned}
Q_{\mathrm{D}_{0}}-Q_{\mathrm{D}_{0}+} & =\sqrt{n_{\mathrm{D}}}\left(d_{\mathrm{D}_{0}}-d_{\mathrm{D}_{0}+}\right), \\
Q_{\mathrm{A}_{0}{ }^{-}}-Q_{\mathrm{A}_{0}} & =\sqrt{n_{\mathrm{A}}}\left(d_{\mathrm{A}_{0}{ }^{-}}-d_{\mathrm{A}_{0}}\right),
\end{aligned}
$$

and a horizontal offset

$$
\begin{aligned}
Q_{\mathrm{et}, \mathrm{D}_{0}{ }^{+} \mathrm{A}_{0}-}-Q_{\mathrm{et}, \mathrm{D}_{0} \mathrm{~A}_{0}} & =Q_{\mathrm{et}, \mathrm{D}_{0}+\mathrm{A}_{0^{-}}} \\
& =\sqrt{n_{\mathrm{D}}\left(d_{\mathrm{D}_{0}}-d_{\mathrm{D}_{0}}\right)^{2}+n_{\mathrm{A}}\left(d_{\mathrm{A}_{0^{-}}}-d_{\mathrm{A}_{0}}\right)^{2}} .
\end{aligned}
$$

For excited states of $\mathrm{DA}$ and $\mathrm{D}^{+} \mathrm{A}^{-}$, the diabatic energy surfaces are

$$
\begin{aligned}
E_{\mathrm{D}_{i} \mathrm{~A}_{j}}\left(Q_{\mathrm{D}}, Q_{\mathrm{A}}\right)= & E_{\mathrm{D}_{i} \mathrm{~A}_{j}, e}+\frac{1}{2} k_{\mathrm{D}}\left(Q_{\mathrm{D}}-Q_{\mathrm{D}_{i}}\right)^{2}+\frac{1}{2} k_{\mathrm{A}}\left(Q_{\mathrm{A}}-Q_{\mathrm{A}_{j}}\right)^{2} \\
E_{\mathrm{D}_{k}+\mathrm{A}_{\ell^{-}}}\left(Q_{\mathrm{D}}, Q_{\mathrm{A}}\right)= & E_{\mathrm{D}_{k}+\mathrm{A}_{\ell^{-}, e}}+\frac{1}{2} k_{\mathrm{D}}\left(Q_{\mathrm{D}}-Q_{\mathrm{D}_{k}}\right)^{2} \\
& +\frac{1}{2} k_{\mathrm{A}}\left(Q_{\mathrm{A}}-Q_{\mathrm{A}_{\ell^{-}}}\right)^{2}
\end{aligned}
$$

The energy offsets of DA are the sums of the minimum-tominimum excitation energies from the ground state to the $i$ excited state of $\mathrm{D}$ and from the ground state to the $j$ excited state of A: $E_{\mathrm{D}_{i} \mathrm{~A}_{j}, e}=\left(E_{\mathrm{D}_{i}, e}-E_{\mathrm{D}_{0}, e}\right)+\left(E_{\mathrm{A}_{j} e}-E_{\mathrm{A}_{0}, e}\right)$. Correspondingly, the energy offsets of $\mathrm{D}^{+} \mathrm{A}^{-}$are the sums of the minimum-tominimum excitation energies from the ground state to the $k$ excited state of $\mathrm{D}^{+}$and from the ground state to the $\ell$ excited state of $\mathrm{A}^{-}$, plus the ground state energy offset $E_{\mathrm{D}^{0}{ }^{+} \mathrm{A}_{0}-, e, \text { which }}$ fulfils eqn (25): $E_{\mathrm{D}_{k^{+}}+\mathrm{A}_{\ell^{-}, e}}=E_{\mathrm{D}_{0}{ }^{+} \mathrm{A}_{0}^{-}, e}+\left(E_{\mathrm{D}_{k}^{+}, e}-E_{\mathrm{D}_{0}, e}\right)+\left(E_{\mathrm{A}_{\ell}{ }^{-}, e}-\right.$ $E_{\mathrm{A}_{0}-e}$ ). The $\mathrm{D}^{+} \mathrm{A}^{-}$ground state energy offset $E_{\mathrm{D}_{0}{ }^{+} \mathrm{A}_{0}{ }^{-}, e}$ is the only parameter of the model that depends on the donor-acceptor distance $d_{\mathrm{DA}}$. This means that when two or more DA pairs made of the same elements coexist in the same host with different D-A distances, $d_{\mathrm{DA}}$ and $d_{\mathrm{DA}^{\prime}}$, their MMCT manifolds $E_{\mathrm{D}_{k}{ }^{+} \mathrm{A}_{-}-}$are identical and shifted in energy with respect to one another. Eqn (25) gives $\left(q_{\mathrm{A}}-q_{\mathrm{D}}-1\right)\left(1 / d_{\mathrm{DA}}-1 / d_{\mathrm{DA}^{\prime}}\right)$ for the shift.

In general, there will be one reaction coordinate for each $\mathrm{D}_{i} \mathrm{~A}_{j}-\mathrm{D}_{k}{ }^{+} \mathrm{A}_{\ell}{ }^{-}$combination. However, if the horizontal offsets between different states of DA are much smaller than the MMCT horizontal offset, it is not a bad approximation to use the ground state reaction coordinate eqn (27) for all the states. In this case, we have

$$
\begin{gathered}
E_{\mathrm{D}_{i} \mathrm{~A}_{j}}\left(Q_{\mathrm{et}}\right)=E_{\mathrm{D}_{i} \mathrm{~A}_{j}, e}+\frac{1}{2} k_{\mathrm{et}}\left(Q_{\mathrm{et}}-Q_{\mathrm{et}, \mathrm{D}_{0} \mathrm{~A}_{0}}\right)^{2} \\
E_{\mathrm{D}_{\mathrm{k}}+\mathrm{A}_{\ell^{-}}}\left(Q_{\mathrm{et}}\right)=E_{\mathrm{D}_{k}+\mathrm{A}_{\ell^{-}, e}}+\frac{1}{2} k_{\mathrm{et}}\left(Q_{\mathrm{et}}-Q_{\mathrm{et}, \mathrm{D}_{0}+\mathrm{A}_{0^{-}}}\right)^{2} .
\end{gathered}
$$

Summarizing, eqn (35), together with eqn (33), or in a more general case with eqn (30), constitutes the MMCT configuration coordinate (diabatic) diagram of the $\mathrm{DA}$ and $\mathrm{D}^{+} \mathrm{A}^{-}$metal-metal pairs in a host.

Alternatively, if the horizontal offsets between different states of either DA or $\mathrm{D}^{+} \mathrm{A}^{-}$are taken into account, then the 
MMCT configuration coordinate diagram results from evaluating eqn (34) along the reaction coordinate of eqn (26), (27) and (32). If the reaction coordinate of a set of excited states $\mathrm{D}_{i} \mathrm{~A}_{j}-\mathrm{D}_{k}{ }^{+} \mathrm{A}_{\ell}{ }^{-}$is taken as the configuration coordinate, instead of the ground state combination $\mathrm{D}_{0} \mathrm{~A}_{0}-\mathrm{D}_{0}{ }^{+} \mathrm{A}_{0}{ }^{-}$, then, eqn (26) and (27) are still valid to define such a coordinate, as long as $Q_{\mathrm{D}_{0}}, Q_{\mathrm{A}_{0}}, Q_{\mathrm{D}_{0}}$, and $Q_{\mathrm{A}_{0}-}$, are substituted by the corresponding $Q_{\mathrm{D}_{i}}, Q_{\mathrm{A}_{j}}, Q_{\mathrm{D}_{k}}$, and $Q_{\mathrm{A}_{\ell}-}$.

\section{B. MMCT configuration coordinate diagram of $\mathrm{Ce}^{3+} / \mathrm{Yb}^{3+}$ in YAG}

In Fig. 6 we show a MMCT configuration coordinate diagram of $\mathrm{Ce}^{3+} / \mathrm{Yb}^{3+}$ in YAG, which results from representing eqn (34) along the ground state electron transfer reaction coordinate defined by eqn (26), (27), and (32). The representation along the $\mathrm{Ce}^{3+}\left(5 \mathrm{~d}_{1}{ }^{1}\right)-\mathrm{Yb}^{3+}\left({ }^{2} \mathrm{~F}_{7 / 2}\right) \rightarrow \mathrm{Ce}^{4+}-\mathrm{Yb}^{2+}$ reaction coordinate in the same scale is hard to distinguish at sight. We used the following data: (1) the $E_{\mathrm{D}_{i} \mathrm{~A}_{j}, e}=E_{e}\left(\mathrm{Ce}_{i}{ }^{3+}-\mathrm{Yb}_{j}{ }^{3+}\right)$ energy offsets were obtained from the experimental excitation energies of $\mathrm{Ce}^{3+}$ and $\mathrm{Yb}^{3+}$, which are shown in Table 1. Since we do not have empirical data on the minimum-to-minimum $\mathrm{Ce}^{3+}$-to- $\mathrm{Yb}^{3+}$ charge transfer excitation energy, we treat it here as an empirical parameter such that it provides a diagram consistent with the experiments; hence, we used $E_{\mathrm{D}_{0}{ }^{+} \mathrm{A}_{0}{ }^{-}, e}=E_{e}\left(\mathrm{Ce}^{4+}-\mathrm{Yb}^{2+}\right)=14000 \mathrm{~cm}^{-1}$. (2) We used $d_{\mathrm{A}_{0}-}-d_{\mathrm{A}_{0}}=d_{\mathrm{Yb}^{2+} \mathrm{O}^{-}}-d_{\mathrm{Yb}^{3+} \mathrm{O}}=0.14 \AA$, as in Section III.B, and
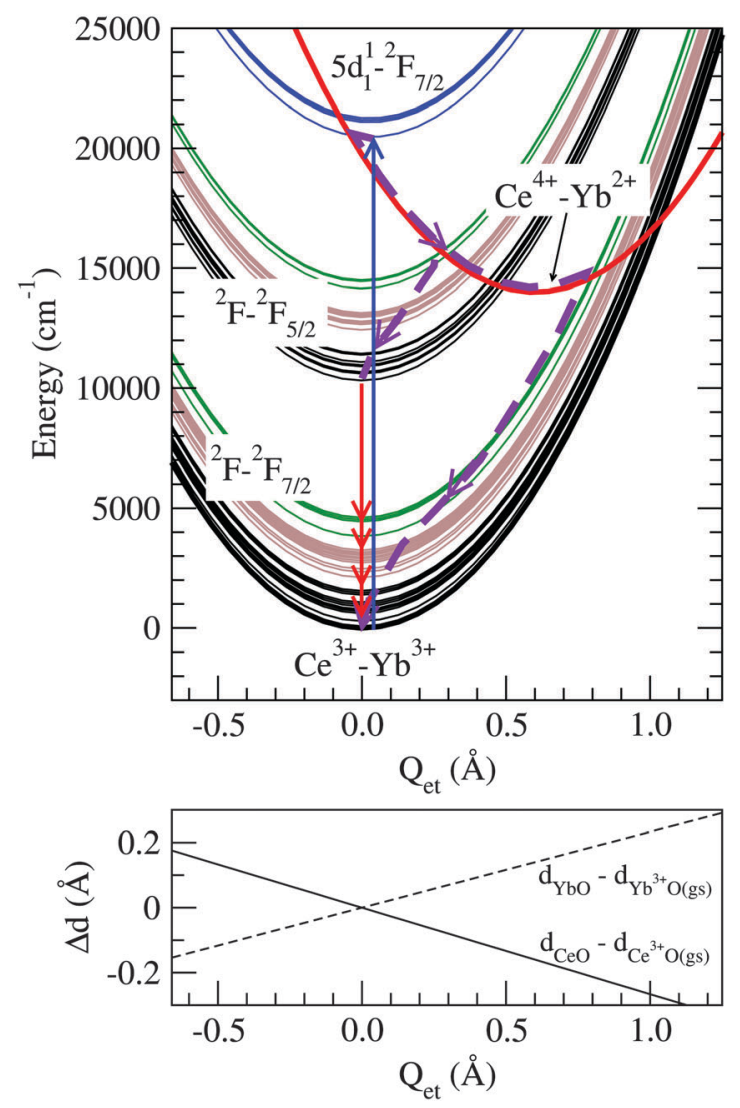

Fig. 6 MMCT configuration coordiante diagram of $\mathrm{Ce}^{3+} / \mathrm{Yb}^{3+}$ pairs in YAG. The following processes are indicated: $\mathrm{Ce}^{3+}$ lowest $4 \mathrm{f} \rightarrow 5 \mathrm{~d}$ absorption (blue arrow); energy transfer to the ${ }^{2} \mathrm{~F}_{5 / 2}$ excited state of $\mathrm{Yb}^{3+}$ and non-radiative decay to the ground states of $\mathrm{Ce}^{3+}$ and $\mathrm{Yb}^{3+}$ trhough the $\mathrm{Ce}^{4+}-\mathrm{Yb}^{2+} \mathrm{MMCT}$ state (dashed violet line); and $\mathrm{Yb}^{3+} 4 \mathrm{f} \rightarrow 4 \mathrm{f}$ emission (red arrows).
$d_{\mathrm{D}_{0}}-d_{\mathrm{D}_{0}{ }^{+}}=d_{\mathrm{Ce}^{3+} \mathrm{O}^{-}}-d_{\mathrm{Ce}^{4+} \mathrm{O}}=0.16 \AA$, using the same procedure as in $\mathrm{Yb}^{2+} / \mathrm{Yb}^{3+}$ (90\% of the difference between the ionic radii of $\mathrm{Ce}^{3+}$ and $\mathrm{Ce}^{4+}$ in coordination 8, $1.143 \AA$ and $0.97 \AA$ respectively. ${ }^{18}$ ). We used the same Ce-O distance offset in all $4 \mathrm{f}^{1}$ states of $\mathrm{Ce}^{3+}$ and $\mathrm{a}-0.02 \AA$ offset for the lowest $5 \mathrm{~d}^{1}$ state (Table 1 ), slightly larger than the $-0.014 \AA$ found in ab initio calculations in $\mathrm{YAG}: \mathrm{Ce}^{3+}$, which has been considered to be underestimated. ${ }^{23}$ (3) The donor and acceptor force constants are $k_{\mathrm{D}}=\mu \omega_{\mathrm{D}}^{2}$ and $k_{\mathrm{A}}=\mu \omega_{\mathrm{A}}^{2}$, with $\mu=$ $m(\mathrm{O})=15.999 \mathrm{amu}$. We used $\bar{\nu}_{\mathrm{D}}=\omega_{\mathrm{D}} /(2 \pi c)=210 \mathrm{~cm}^{-1}$, which is $5 \%$ larger than the $200 \mathrm{~cm}^{-1}$ vibrational sequence found in ref. 17 for YAG: $\mathrm{Ce}^{3+}$ (it corresponds to using a common force constant for $\mathrm{Ce}^{3+}$ and $\mathrm{Ce}^{4+} 10 \%$ larger than that of $\mathrm{Ce}^{3+}$; the force constant is expected to be larger in $\mathrm{Ce}^{4+}$ than in $\left.\mathrm{Ce}^{3+}\right)$. And we used $\bar{\nu}_{\mathrm{A}}=\omega_{\mathrm{A}} /(2 \pi c)=$ $310 \mathrm{~cm}^{-1}$, which is the common vibrational frequency for $\mathrm{Yb}^{2+}$ and $\mathrm{Yb}^{3+}$ that we used in Section III.B.

In the MMCT configuration coordinate diagram, we observe the states of the $\mathrm{Ce}^{3+}-\mathrm{Yb}^{3+}$ pair, which have been discussed above, and, crossing them, the ground state of the $\mathrm{Ce}^{4+}-\mathrm{Yb}^{2+}$ pair, with a horizontal offset of $0.60 \AA$ (eqn (33)). This diagram is basically consistent with the experiments and the interpretations given in ref. 3 . The lowest $\mathrm{Ce}^{3+}\left(5 \mathrm{~d}_{1}{ }^{1}\right)-\mathrm{Yb}^{3+}\left({ }^{2} \mathrm{~F}_{7 / 2}\right)$ state can decay nonradiatively to the $\mathrm{Ce}^{4+}-\mathrm{Yb}^{2+}$ MMCT state with a small energy barrier. This barrier is $73 \mathrm{~cm}^{-1}$ and the crossing is produced on the left side of the $\mathrm{Ce}^{3+}\left(5 \mathrm{~d}_{1}{ }^{1}\right)-\mathrm{Yb}^{3+}\left({ }^{2} \mathrm{~F}_{7 / 2}\right)$ minimum with the above data; although the energy of the barrier can change with the parameters of the model, the basic interpretation is mantained for a relatively wide range around the present data. Next, the $\mathrm{Ce}^{4+}-\mathrm{Yb}^{2+}$ MMCT state can decay directly to the $\mathrm{Ce}^{3+}\left(4 \mathrm{f}^{1}\right)-\mathrm{Yb}^{3+}\left({ }^{2} \mathrm{~F}_{5 / 2}\right)$ manifold, which can yield $\mathrm{Yb}^{3+2} \mathrm{~F}_{5 / 2} \rightarrow{ }^{2} \mathrm{~F}_{7 / 2}$ emission. This is consistent with the observations of energy transfer from $\mathrm{Ce}^{3+}$ to $\mathrm{Yb}^{3+}$ in YAG:Ce, $\mathrm{Yb}$, with its temperature dependence, and with the $\mathrm{Yb}^{3+}$ emission not showing rise time, so that it supports the given interpretation as due to a thermally activated decay through an intermediate $\mathrm{Ce}^{4+}-\mathrm{Yb}^{2+}$ charge transfer state, ${ }^{3}$ and complements it with a more detailed description. A value of $E_{e}\left(\mathrm{Ce}^{4+}-\mathrm{Yb}^{2+}\right)$ around $2000 \mathrm{~cm}^{-1}$ higher is also consistent with the experiments: e.g. a value of $16000 \mathrm{~cm}^{-1}$ gives a $30 \mathrm{~cm}^{-1}$ barrier and a crossing on the right side of the minimum. Note that according to eqn (25), several $E_{e}\left(\mathrm{Ce}^{4+}-\mathrm{Yb}^{2+}\right)$ values associated to different $\mathrm{Ce}-\mathrm{Yb}$ distances can coexist in the material.

An additional interesting feature was observed in the experiments of ref. 3: the intensity of the $\mathrm{Yb}^{3+} 4 \mathrm{f} \rightarrow 4 \mathrm{f}$ emission as excited with the $\mathrm{Ce}^{3+} 4 \mathrm{f} \rightarrow 5 \mathrm{~d}$ absorption strongly decreases above $110 \mathrm{~K}$, after the initial increase with temperature due to the thermally activated crossing to the $\mathrm{Ce}^{4+}-\mathrm{Yb}^{2+}$ MMCT state. The crossing between the $\mathrm{Ce}^{4+}-\mathrm{Yb}^{2+}$ MMCT state and the lowest $\mathrm{Ce}^{3+}\left(4 \mathrm{f}^{1}\right)-\mathrm{Yb}^{3+}\left({ }^{2} \mathrm{~F}_{7 / 2}\right)$ manifold was suggested as a possible explanation. The present MMCT configuration coordinate diagram does not rule out such an explanation because the crossing exists, although it has a relatively high barrier $\left(590 \mathrm{~cm}^{-1}\right.$ with the present data). However, the consideration of both, the MMCT diagram of $\mathrm{Ce}^{3+}-\mathrm{Yb}^{3+}$ in YAG (Fig. 6) and the IVCT diagram of $\mathrm{Yb}^{2+}-\mathrm{Yb}^{3+}$ in YAG (Fig. 4), suggests an alternative explanation: the $\mathrm{Ce}^{3+}$-to- $\mathrm{Yb}^{3+}$ MMCT produced after the $\mathrm{Ce}^{3+} 4 \mathrm{f} \rightarrow 5 \mathrm{~d}$ absorption increases the probability of formation of $\mathrm{Yb}^{2+}-\mathrm{Yb}^{3+}$ pairs, hence, of quenching 
the $\mathrm{Yb}^{3+}$ if $\rightarrow$ 4f emission via IVCT non-radiative decay, as discussed in Section III.B.

\section{Conclusions}

Quantitative configuration coordinate diagrams for intervalence charge transfer states of mixed valence pairs and metal-to-metal charge transfer states of heteronuclear pairs of dopant ions in solid hosts have been introduced and discussed in detail. They are obtained with the use of vibrational frequencies and excitation energies of single-ion active centers, together with differences between ion-ligand distances of the single-ion donor and acceptor centers. These data are attainable empirically, either from direct measurements or from estimations, e.g. based on ionic radii, and they can be calculated using $a b$ initio methods. The IVCT configuration coordinate diagram of the $\mathrm{Yb}^{2+} / \mathrm{Yb}^{3+}$ mixed valence pair in Yb-doped YAG, and the MMCT configuration coordinate diagram of the $\mathrm{Ce}^{3+} / \mathrm{Yb}^{3+}$ heteronuclear pair in Ce,Yb-codoped YAG have been obtained and discussed. Empirical data of the individual ions doped in YAG have been used for this purpose.

The analysis of the $\mathrm{Yb}^{2+} / \mathrm{Yb}^{3+}$ IVCT diagram suggests that quenching of the $\mathrm{Yb}^{3+} 4 \mathrm{f} \rightarrow 4 \mathrm{f}$ emission takes place by means of IVCT non-radiative decay in $\mathrm{Yb}^{2+} / \mathrm{Yb}^{3+}$ pairs.

The analysis of the $\mathrm{Ce}^{3+} / \mathrm{Yb}^{3+}$ MMCT diagram supports a previous interpretation of energy transfer from $\mathrm{Ce}^{3+}$ to $\mathrm{Yb}^{3+}$ in Ce,Yb-codoped YAG, after $\mathrm{Ce}^{3+} 4 \mathrm{f} \rightarrow 5 \mathrm{~d}$ excitation, via a $\mathrm{Ce}^{4+}-\mathrm{Yb}^{2+}$ MMCT state. The diagram provides the details of this process. The energy of the structurally relaxed $\mathrm{Ce}^{4+}-\mathrm{Yb}^{2+}$ pair is estimated to lie at either about $14000 \mathrm{~cm}^{-1}$ or $16000 \mathrm{~cm}^{-1}$ above the structurally relaxed $\mathrm{Ce}^{3+}-\mathrm{Yb}^{3+}$ pair. According to the diagram, there is a higher probability of nonradiative decay from the intermediate $\mathrm{Ce}^{4+}-\mathrm{Yb}^{2+}$ pair to the excited $\mathrm{Ce}^{3+}\left(4 \mathrm{f}^{1}\right)-\mathrm{Yb}^{3+}\left({ }^{2} \mathrm{~F}_{5 / 2}\right)$ manifold than to the ground $\mathrm{Ce}^{3+}\left(4 \mathrm{f}^{1}\right)-\mathrm{Yb}^{3+}\left({ }^{2} \mathrm{~F}_{7 / 2}\right)$ manifold of the $\mathrm{Ce}^{3+}-\mathrm{Yb}^{3+}$ pair. Altogether, the two diagrams suggest that the temperature quenching of the $\mathrm{Yb}^{3+} 4 \mathrm{f} \rightarrow$ 4f emission excited with $\mathrm{Ce}^{3+} 4 \mathrm{f} \rightarrow 5 \mathrm{~d}$ absorption is due to the formation of $\mathrm{Yb}^{2+}-\mathrm{Yb}^{3+}$ pairs after MMCT from $\mathrm{Ce}^{3+}-$ to- $-\mathrm{Yb}^{3+}$ in $\mathrm{Ce}^{3+}-\mathrm{Yb}^{3+}$ pairs.

\section{Acknowledgements}

This work was partly supported by a grant from Ministerio de Economa y Competitivad, Spain (Dirección General de Investigación y Gestión del Plan Nacional de I+D+I, MAT2011-24586 and MAT2014-54395-P).

\section{References}

1 J. W. Verhoeven, Pure Appl. Chem., 1996, 68, 2223.

2 G. Blasse, Struct. Bonding, 1991, 76, 153.

3 D. C. Yu, F. T. Rabouw, W. Q. Boon, T. Kieboom, S. Ye, Q. Y. Zhang and A. Meijerink, Phys. Rev. B: Condens. Matter Mater. Phys., 2014, 90, 165126.

4 E. Pinel, P. Boutinaud and R. Mahiou, J. Alloys Compd., 2004, 380, 225.

5 G. C. Allen and N. S. Hush, Prog. Inorg. Chem., 1967, 8, 357.

6 M. Robin and P. Day, Adv. Inorg. Chem. Radiochem., 1968, 10, 247.

7 W. van Schaik, S. Lizzo, W. Smit and G. Blasse, J. Electrochem. Soc., 1993, 140, 216.

8 C. Wickleder, Z. Naturforsch., 2002, 57b, 901.

9 L. Seijo and Z. Barandiarán, J. Chem. Phys., 2014, 141, 214706.

10 Z. Barandiarán and L. Seijo, J. Chem. Phys., 2014, 141, 234704.

11 E. Loh, Phys. Rev., 1969, 184, 348.

12 H. Witzke, D. S. McClure and B. Mitchell, in Luminescence of Crystals, Molecules, and Solutions, ed. F. E. Williams, Plenum, New York, 1973, p. 598.

13 S. B. Piepho, E. R. Krausz and P. N. Schatz, J. Am. Chem. Soc., 1978, 100, 2996.

14 R. A. Buchanan, K. A. Wickersheim, J. J. Pearson and G. F. Herrmann, Phys. Rev., 1967, 159, 245.

15 H. Przybylińska, C.-G. Ma, M. G. Brik, A. Kamińska, P. Sybilski, A. Wittlin, M. Berkowski, Y. Zorenko and V. Gorbenko, et al., Appl. Phys. Lett., 2013, 102, 241112.

16 L. Seijo and Z. Barandiarán, Phys. Chem. Chem. Phys., 2014, 16, 3830 .

17 V. Bachmann, C. Ronda and A. Meijerink, Chem. Mater., 2009, 21, 2077.

18 R. D. Shannon, Acta Crystallogr., Sect. A: Cryst. Phys., Diffr., Theor. Gen. Crystallogr., 1976, 32, 751.

19 L. Seijo and Z. Barandiarán, Int. J. Quantum Chem., 1996, 60, 617. 20 A. Lupei, V. Enaki, V. Lupei, C. Presura and A. Petraru, J. Alloys Compd., 1998, 275-277, 196.

21 P. Yang, P. Deng and Z. Yin, J. Lumin., 2002, 97, 51.

22 C. W. Struck and W. H. Fonger, J. Lumin., 1975, 10, 1.

23 J. Gracia, L. Seijo, Z. Barandiarán, D. Curulla, H. Niemansverdriet and W. van Gennip, J. Lumin., 2008, 128, 1248. 